OPEN ACCESS

University of Dundee

\title{
A methodological approach to assess the hazard of underground cavities subjected to environmental weathering
}

Castellanza, Riccardo ; Lollino, Piernicola; Ciantia, Matteo

Published in:

Tunnelling and Underground Space Technology

DOI:

10.1016/j.tust.2018.08.041

Publication date:

2018

Licence:

CC BY-NC-ND

Document Version

Peer reviewed version

Link to publication in Discovery Research Portal

Citation for published version (APA):

Castellanza, R., Lollino, P., \& Ciantia, M. (2018). A methodological approach to assess the hazard of underground cavities subjected to environmental weathering. Tunnelling and Underground Space Technology, 82, 278-292. https://doi.org/10.1016/j.tust.2018.08.041

\section{General rights}

Copyright and moral rights for the publications made accessible in Discovery Research Portal are retained by the authors and/or other copyright owners and it is a condition of accessing publications that users recognise and abide by the legal requirements associated with these rights.

- Users may download and print one copy of any publication from Discovery Research Portal for the purpose of private study or research.

- You may not further distribute the material or use it for any profit-making activity or commercial gain.

- You may freely distribute the URL identifying the publication in the public portal.

Take down policy

If you believe that this document breaches copyright please contact us providing details, and we will remove access to the work immediately and investigate your claim. 
1 A methodological approach to assess the hazard of underground cavities subjected to environmental weathering.

Castellanza Riccardo ${ }^{1}$, Lollino Piernicola², Ciantia Matteo 3

${ }^{1}$ Department of Earth and Environmental Sciences, University of Milano-Bicocca, Milano (ITALY) (riccardo.castellanza@unimib.it)

${ }^{2}$ IRPI - Consiglio Nazionale delle Ricerche, Bari (ITALY) (p.lollino@ba.irpi.cnr.it)

${ }^{3}$ School of Science and Engineering, University of Dundee, Dundee (m.o.ciantia@dundee.ac.uk)

Keywords: methodological approach, environmental weathering, soft rocks, numerical modelling, hazard assessment

\section{Abstract}

Soft highly porous carbonate rocks such, as calcarenites, and soluble sulphate rocks, as gypsum, are very common in the Mediterranean region and, due to their microstructure and chemical composition, are prone to water induced weathering mechanisms. Cliffs, underground cavities and other morphological features in such formations are hence affected by intense erosion phenomena and weathering processes responsible of unexpected collapses and sinkholes. Just considering the Apulian region (Italy), 150 sinkholes have been recorded since 1925, with increasing frequency since 2000 (Fiore et al. 2018). The geosystem's failure is often the short or long-term result of a very complex hydro-chemo mechanical process taking place at the micro-scale which can be detected and analysed by means of field and laboratory experimental test campaigns. Therefore, stability problems are often related to changes of the mechanical properties of the rock forming the cave caused by environmental weathering processes, despite the external boundary conditions are not changing with time. The paper deals with the assessment of hazard associated to the stability of abandoned underground caves, which is nowadays frequently required for land and urban planning activities. A methodological approach for hazard assessment based on a step-by-step procedure is proposed. This includes in-situ surveys, laboratory experimental studies, theoretical analyses and finally numerical investigations. The approach derives from the experience developed from several case studies analysed by the authors. In this work, two of these are presented. The first one concerns the stability of an anthropic cavity in a calcarenite formation which is affected by a water induced short-term and long-term debonding processes. The second one regards the stability of a three- 
level abandoned gypsum mine, the lowest level being partially flooded by water. The methodological procedure aims to evaluate the factors controlling the change of the mechanical properties of the rock leading to failure, so that efficient remediation measures can be designed in order to avoid any further decay of the rock mass stability with time.

The proposed methodological approach, validated on real case studied, shows the convenience of performing advanced experimental, theoretical and numerical studies to properly assess the hazard in space and time and to better design the mitigation measures if they are required. The adoption of the proposed approach reduced the remediation costs of the second case study to one order of magnitude.

\section{Introduction}

The assessment of hazard associated to the stability of man-made underground caves, which were exploited and abandoned some decades ago, is still nowadays frequently underestimated during land and urban planning activities. This is generally related to the loss of historical memory concerning the existence of old underground caves in land management processes, as well as the change of the boundary conditions working on the cave systems that leads to the consequent variation of the rock material properties over time, even in a relatively short time. High risk conditions are also enhanced by the fast development of urban areas, which gives frequently rise to the existence of buildings and infrastructures lying over caves that cannot be considered as safe. Recent case studies of collapse of man-made underground caves, with consequent sinkholes affecting urbanized areas, are well described in the literature, as for example those involving the calcarenite caves in Southern Italy (Parise and Lollino 2011, Vattano et al. 2013), the metal mining caves in Canada (Betournay, 2009), the siltstone Longyou caverns in China (Li et al. 2009, Yang et al. 2011), the limestone mines in the Netherlands and Belgium (Bekendam 1998; Van Den Eeckhaut et al. 2007).

Instability of caves is frequently associated to the occurrence of degradation of the mechanical properties of the rock surrounding the cave as a consequence of environmental processes. In particular, water infiltration from ground surface or pipe leakage, increment of relative humidity of the cave environment, as well as more extreme cave flooding are all related to the increment of the degree of saturation of the rock over time and the consequent rock degradation (Figure 1). This is 
particularly true for those rocks that are highly sensitive to the interaction with water, as for example evaporitic rocks and soft porous rocks. Several studies have been proposed on this subject, as for example those concerning the iron ore abandoned mines in Lorraine, as discussed in Grgic et al. (2006), the aging of gypsum in underground mines (Auvray et al. 2004, Castellanza et al. 2010) and the works on the debonding processes affecting the calcarenite outcropping in Southern Italy (Andriani and Walsh, 2007; Ciantia and Hueckel, 2013; Ciantia et al. 2014, 2015).

The methods for the assessment of stability of underground caves that are available in the scientific literature can be generally classified according to three classes: phenomenological, analytical and numerical approaches. Phenomenological methods are generally based on abaci that show areas representing stable or unstable cave configurations on the basis of geometrical parameters of the cave and strength parameters of the rock, as derived from a large number of case studies (Potvin and Milne 1992, Nickson 1992, Carter 1992, Goodings and Abdulla 2002). Analytical closed-form solutions have been instead widely used to calculate elastic solutions for roofs with very simple geometries, such as caves with circular or rectangular shape (Obert and Duvall 1967, Jaeger and Cook 1979), followed by closed form solutions accounting for the elasto-plastic behaviour of the rock material (Lippmann 1971, Ribacchi and Riccioni 1977, Brown et al. 1983, Detournay and Fairhurst 1987, Panet 1995, Carranza-Torres and Fairhurst 1999, Gesualdo et al. 2001, Diederichs and Kaiser 1999).

Recently, numerical modelling has provided a powerful tool to explore the stress-strain state within the rock mass around the cavities and the corresponding displacement field induced by a specific loading condition or changes of boundary conditions, also adopting advanced non-linear constitutive models. To mention a few, Mortazavi et al. (2009) propose a numerical investigation of the failure mechanism of rock pillars in underground openings by taking into account the effect of pillar geometry and pillar strength parameters for typical situations existing in the Canadian mines. Bekendam (1998) studied the stability of calcarenite and limestone mine pillars in the Netherlands by means of two-dimensional elasto-plastic finite element (FE) models, also implementing timedependent creep processes, whereas Parise and Lollino (2011) highlighted with the same 2D FE approach the role of the degradation processes of the limestone and calcarenite rock surrounding caves in Southern Italy in the development of sinkholes. Ferrero et al. (2010) detect the areas of highest stress concentration and calculate the corresponding safety factors of the most loaded pillars by means of 3D FE analysis of old underground calcareous quarries in the Western Alps (Italy). Ghabezloo and Pouya (2004) perform a FE analysis aimed at studying roof stability of limestone 
caves in France due to tensile strength degradation induced by karst processes. Diederichs (2003) investigates rock fracture mechanisms and global collapse of caves by means of the distinct element method, whereas Wang et al. (2011) explore the failure mechanisms of underground cave pillars by means of the application of the Rock Fracture Propagation Analysis. From a theoretical point of view, a well-consolidated experience has been gathered in the numerical application of simple elasto-plastic constitutive models, such as those implementing the Mohr-Coulomb or the HoekBrown failure criterion (Pelizza et al. 2000, Zhang et al. 2016, Fazio et al. 2017, Jiang et al. 2017). Trinh and Jonsson (2013) developed an elasto-plastic finite element model of an underground cavern room in hard rocks, also accounting for the effects of reinforced bolts. On the other hand, more advanced constitutive models have been recently implemented in numerical codes to simulate the variation of the rock mechanical properties due to environmental factors and the coupled chemo-mechanical processes associated (Fernandez-Merodo et al. 2007; Grgic et al. 2006; Ciantia and Castellanza 2016; Tamagnini and Ciantia 2016).

Based on the aforementioned technological development, the paper aims to propose a procedure of hazard assessment for underground caves, based on the experience and the theoretical research developed by the Authors in some recent case histories. In particular, a methodological approach based on in-situ surveys (including the use of Laser-Scan techniques to define model geometry), laboratory and field investigations, theoretical and numerical analyses are presented in the following. Afterwards, two case studies are discussed within the framework of the procedure proposed and some conclusions regarding the evolution of the cave stability over time are drawn accordingly.

\section{Methodological approach}

The proposed methodological approach for the quantitative assessment of failure susceptibility associated to the presence of underground caves follows a procedure formed of six steps (Figure 2):

1) In-situ survey: preliminary field surveys should be carried out both inside the caves and at the ground surface according to either conventional topographical survey methods or advanced tools, as laser-scan techniques, in order to define a three-dimensional geometrical model of the overall area; then, a detailed geological and hydro-geological analysis should follow to define the lithological model, the geo-structural setting and the eventual existence of hydro-geological features, as water circulation or infiltration from ground surface; 
2) Choice of the conceptual model: this second stage should be aimed at defining the general features of the real problem's schematization and is represented by the choice between a 2D or a 3D model geometry (based on the eventual existence of plane-strain conditions), as well as the choice between a continuum or a discontinuum model, according to the eventual existence of relevant joints;

3) Experimental analysis: this step is finalized at defining the factors that play a major role in involved material, susceptibility of the rock to weathering and degradation processes, propagation of weathering according to sharp-front or preferential ways, etc. At this stage, accurate laboratory tests aimed at characterizing the most important physical and mechanical properties of both the intact and the weathered rock material (unit weight, porosity, water content, elastic stiffness, uniaxial compressive strength, tensile strength, shear strength at high stress levels), as well as defining how the weathering degree changes with time and in space, should be performed. In particular, the laboratory tests should give an indication of the degree of in-situ weathering occurred from the time of cave excavation to the present, the thickness of the layer affected by the weathering process, the in-situ environmental conditions as well as the evolution of the weathering process; to this purpose, artificial weathering scenarios can be useful to define the law of variation of the rock strength in the short- and in the long-term. In particular, it is convenient to define: i) a short term weathering to describe the quick reduction of geomechanical properties of the rock material from dry to wet conditions; ii) a long term weathering associated to a relatively slow weathering process usually induced by chemical dissolution processes.

The results of the experimental analysis are then used to both initialize the initial conditions of the numerical model and to define a set of representative environmental scenarios in order to assess the cave stability in the short- and in the long-term.

4) Theoretical analysis: The mathematical model needed to describe the main features of the geomechanical behaviour of the rock, i.e. the constitutive model, should be here defined and calibrated using the experimental test results. Due to the large difference of timescales between mechanical and chemical processes (Ciantia and Hueckel, 2013) the assumption of uncoupled chemo-mechanical behaviour is considered to be reasonable (Ciantia et al, 2014). The use of elastic constitutive models, adopted for the application of simple analytical 
methods in preliminary hazard assessment (see section \#1), should be avoided as the elastoplastic behaviour that characterises any geomaterial should be properly taken into account. A Mohr-Coulomb elastic-perfectly plastic model is deemed to be appropriate for problems where shear type of failure is dominant (when the mean effective stress, $p^{\prime}$, is low), whereas an elasto-plastic model with the Hoek-Brown failure criterion (Hoek and Brown, 1997) approach, for the influence of the eventual rock mass fracturing state or the non-linearity of the failure envelope at high p'. In a complex 3-D boundary value problem these simple constitutive models could be correctly used only to detect the critical areas where local plastic yielding starts to develop, since the eventual brittle behaviour of the rock material is not accounted for.

Coupled hydro-chemo-mechanical advanced constitutive models could be eventually used to reduce the risk of oversimplification of both the spatio-temporal weathering evolution and the material mechanical behaviour (Ciantia et al., 2018).

5) Numerical analysis: in this stage of the methodology the chosen elasto-plastic constitutive model is used to run FE analyses in order to define a quantitative assessment of the stability of the underground cave in the current state and eventually a possible scenario of the evolution of the stability with time (step \#6: hazard assessment). At this stage, Preliminary results obtained with analytical methods based on elastic theory for either roof or pillar stability problems should be compared with the results of numerical elasto-plastic models. The choice of a 2D or 3D model depends on the eventual existence of plane strain conditions. In case of complex geometries, 3D modelling is mandatory. For those problems where no precise information of specific input data is available, 2-D sensitivity analyses are suggested to highlight the influence of specific factors, as the initial stress state of the rock mass or the flow rule of the constitutive model adopted. In general, the numerical model should be aimed at simulating the current state of the rock mass domain, by implementing the mechanical and hydraulic boundary conditions, the excavation process of the cave and the existing loading conditions.

More sophisticated approach, suitable to describe the brittle failure mechanism of cavities are now suitable to be applied in 2D models (Lollino and Andriani, 2017), although in this 
paper it is shown that the continuum approach is still one of the most convenient tool to perform quantitative hazard assessment analyses especially in 3D.

6) Hazard assessment: If stable conditions result from the model representing the current state of the rock-mass (final result of step \#5: numerical analysis), a strength reduction calculation stage, simulating the weathering mechanisms both for STD and LTD weathering processes, should be performed to derive an indication of the safety factor. This can be done using the $c-\phi$ reduction numerical technique (Griffiths and Lane, 1999; Aliguer et al, 2013). and the other in the long term (LTD). The first can be considered as the result of an imbibition process: water penetrates through the porous structure causing an instantaneous drop in strength (Cherblanc et al, 2016). The second one is the result of the chemical dissolution of the rock mass when interacting with water for long time periods inducing further damage (Ciantia et, al 2015a). The driving scalar variables of this two hydro micro-scale weathering mechanisms were found to be the saturation degree, $S_{r}$, and normalized dissolved mass, $\xi_{\text {dis }}$, respectively (see Ciantia et al, 2014). The concept of non-mechanical softening driven by the two-latter mentioned scalar quantities $\left(S_{r}\right.$ and $\left.\xi_{\text {dis }}\right)$ introduced by Ciantia et al, 2013 using a multiscale approach (see Ciantia and di Prisco, 2016), is extended to the practical methodology of the $c-\phi$ allowing to obtain a physical time evolution of the safety factor (Ciantia et al, 2015b). In fact, as the evolution of the yield locus can be described as a function of saturation degree, $S_{r}$, for the STD process, the dissolved mass, $\xi_{\text {dis }}$, induces in the LTD process a similar shrinkage of the yield locus (Tamagnini and Ciantia, 2016).

On the other hand, as explained by Ciantia and Hueckel (2013), the worst weathering scenario is the one characterized by a rapid saturation and consequent fresh water recycle. Under these conditions, using specific weathering experimental test results that describe the strength evolution with $S_{r}$, for the short term debonding (STD) and physical time for the long term debonding LTD (step \#3), it is possible to build the $c-\phi$ reduction coefficient - time abacus for the intact rock in an uncoupled manner and without having to solving the chemohydraulic problem. Consequently, the classical $c-\phi$ reduction numerical analysis combined with the procedure here presented enables to estimate the evolution with time of the safety factor, $F_{s}(t)$. 
From a conceptual point of view, the stability factor of an ideal man-made cave, $F_{s}$, can be considered as evolving with time according to the scheme proposed in Figure 3. The figure reports that the stability factor of an underground cave at the time of excavation, i.e. initial conditions, is represented by $F_{0}$ and corresponds to the unweathered mechanical properties of the rock material. As weathering process proceeds with time, the stability factor of the cave, $F_{s}(t)$, tends to reduce due to rock mechanical weakening and the corresponding law of variation might be potentially defined by performing numerical analyses implementing different sets of rock mechanical properties corresponding to different steps of the degradation process. Therefore, at time $t_{r}$, when a stability factor of the cave equal to $F_{r}$ has been reached and analysis for remediation is required, two possible approaches for remediation can be followed (Figure 3): 1) structural interventions, aimed at increasing rock mass strength, or 2) conservative interventions, aimed at preventing any further mechanicalweakening weathering process. The first can generally lead to an increment of the stability factor (curve 1), whereas the latter is intended to maintain the cave stability constant over time (curve 2). Frequently, the second option includes preservation of air ventilation, reduction of water infiltration, prevention of chemical dissolution processes, creation of rock surfaces impervious to environmental weathering using specific chemical consolidation products, these being advisable for those cases when environmental preservation is required, as for cultural heritage sites. In this case, the increment of stability factor should be interpreted as the distance between curve (2) and curve (a) leading to rock mass failure, at time $t_{F}$, in Figure 3 . Such conservative interventions should be pursued along with monitoring activities aimed at controlling that the environmental conditions corresponding to curve (2) are effectively maintained in situ. This means that the environmental variables should be monitored as first and the rock mechanical properties should be controlled in order to kept them about constant over time, also by performing in-situ or laboratory tests at regular time intervals.

The following case studies specify in detail the application of the methodology proposed to highlight how the effects of the environmental weathering could be practically evaluated in situ and in laboratory, how these effects can be taken into account using simple constitutive models and how complex three-dimensional finite element analyses could be very useful to assess hazard from a quantitative point of view. All the numerical analyses are run using GTS-NX FEM code (2010) and the NAFEMS (1983) suggestions have been considered for the setup of the analyses. 
In this research, a deterministic approach has been adopted with its inherent limitations. Such drawback leaves room for further research and may be addressed by employing a probabilistic approach (Griffiths and Fenton, 2004; Fenton and Griffiths, 2008; Gong et al. 2018).

\section{Case studies}

Two representative case studies are here presented in order to describe the methodology outlined in the previous section and highlight some criteria which might be adopted in the procedure of hazard assessment of underground caves in urbanized areas. The first case is represented by manmade caves excavated in a calcarenite deposit in the urban area of Canosa di Puglia (Southern Italy), whereas the second one is a large multiple-level cave system formed of pillars and rooms located in San Lazzaro di Savena (BO, Northern Italy). For both the cases, rock is affected by high susceptibility to weathering processes and hazard conditions exist since the cavities lie below a densely urbanised area.

\subsection{Case study \#1: Canosa di Puglia (Southern Italy)}

In this case study the stability of two caves (Figure 4) excavated about two centuries ago within a calcarenite deposit belonging to the "Calcarenite di Gravina" Formation is investigated. The first, cave $A$, is overlaid by an older (B1 in Figure $4 b$ ) and a more recent building (B2 in Figure $4 b$ ); in particular, the recent building is founded on piles that cross the cave and transfer the structural loads below the cave. Cave B is instead characterized by a more complex geometry, with a building located at the ground surface (see Figure 4).

A plan view of the buildings and the cave geometry is shown in Figure $4 \mathrm{~b}$; owing to the complex subsurface geometry, it was decided to carry out a 3D laser-scan survey (see Figure 4c) according to Step \#1 in Figure 2. The advantage of using such technology is the high-accuracy geo-referentiation of the interacting bodies. A geological survey is also performed to define the state of the rock mass, with regard to the eventual existence of joints, local stratigraphy, possible presence of water and evidence of environmental weathering within the cave. The main outcomes of the geological survey indicate that the rock mass can be classified as massive, i.e. no presence of relevant discontinuities, no water circulation is observed around the cave, relative humidity ranges between $60 \%$ and $90 \%$ and temperature is between $12^{\circ}$ and $20^{\circ}$. Based on the results of the geometrical and geological survey (step \#1), the conceptual model, developed according to step \#2, implied the adoption of a 3D FEM analysis aimed at studying the behaviour of the rock mass as a continuum. Owing to the 
homogeneous state of the Calcarenite formation, just few points (see Figure 4b) are chosen for sampling the material to be tested experimentally (Step \#3). 110-mm diameter cores are drilled for a depth of about $70 \mathrm{~cm}$ from the inner surface of the cave; then, 38- $\mathrm{mm}$ and $54-\mathrm{mm}$ diameter samples are retrieved within the larger cores at a distance of 10,20 and $50 \mathrm{~cm}$ from the cave boundary surface in order to assess the variation of the rock mechanical properties with depth from the cave wall, $z_{s}$ in Figure 5.

It is known that calcarenites from southern Italy exhibit high susceptibility to water induced weathering (Castellanza and Nova (2004), Andriani and Walsh (2007), Castellanza et al. (2009)) and therefore, the experimental campaign is aimed at investigating the effects of the two microscale debonding processes that could take place in the short (STD) - and long-term (LTD) (see Ciantia et, al 2014 for details including sample preparation). Referring to the eventual mechanical decay induced by water saturation of the calcarenite (STD) and the slow chemically-induced mechanical decay of the saturated rock (LTD), the following experimental analysis (Step \#3) has been carried out:

- Micro-scale tests (Figure 6), including thin sections, SEM (Scanning Electron Microscopy) and XRPD (X-Ray Powder Diffraction), reveal that: i) the microstructure of the calcarenite is characterized by the presence of diagenetic (DG) and depositional (DP) bonds that connect calcite grains with organogeous origin, as well as ii) an average porosity equal to $n=0.45$ and iii) a $98 \%$ mean composition of calcite;

- STD laboratory weathering is explored by means of Uniaxial Compressive Test (UCT) and Brazilian Test (BT) on dry, partially saturated and saturated (wet) calcarenite ( Figure 7a), and a reduction of both strength and stiffness up to $50 \%$ of the corresponding values representative of dry conditions is recorded after few minutes of soaking of a dry calcarenite specimen (Figure $7 b$ ). Since these tests are thought to reflect the effects of water infiltration in the cave, such a marked reduction should be properly considered for hazard assessment. For details related to saturation process and sample preparation see Ciantia et al. (2014).

- LTD laboratory weathering tests such as "chemical" creep tests on calcarenite specimens subjected to water flux under constant load. For the specific case study, such tests have proved that the DG bonds dissolve very slowly when flushed by water with a $\mathrm{pH}$ value of 7 , thus causing a strength reduction of $5 \%$ after 8 months. On the contrary, if a pH value of 2.8 
is adopted the same strength reduction occurs in just few hours. The LTD tests can be seen as the worst representative weathering scenario of a flooded cave (Ciantia et al. 2014).

- The effects of in-situ weathering were evaluated by performing UCT and BT on saturated specimens retrieved at 10, 20 and $50 \mathrm{~cm}$ from the cave wall (see Figure 5). Despite the significant scatter, the test results, as reported in Figure 8, do not show significant reduction of the rock uniaxial compressive strength (UCS) and stiffness with $z_{s}$. These results suggest that no significant weathering has developed with $z_{s}$ after more than 250 years of exposition to the environmental conditions. Therefore, it can be inferred that if the current environmental conditions $\left(H_{r}\right.$ (relative humidity) $<100 \%$ and no water infiltration) are maintained, the mechanical properties of the rock are supposed to remain constant in these cavities.

The theoretical analysis (step \#4) is carried out on the basis of the results of the experimental analysis performed (step \#3). An elastic-perfectly plastic model with non-associated Mohr-Coulomb (MC) failure criterion and tension cut-off is chosen and consequently calibrated to reproduce the mechanical behaviour of the calcarenite. Despite the curvilinear yield locus generally observed (Ciantia et al. 2014, Figure 9a), at low stress levels the failure envelope of the Gravina calcarenite can be reasonably approximated as linear by using a Mohr-Coulomb yield criterion (Figure 9b). In this case, the main drawback of using perfect plasticity models is the impossibility of capturing the observed brittle behaviour of the calcarenite, so that a more rigorous approach should consider the application of sophisticated constitutive models able to cope with the mechanical and chemical softening process (Nova et al. 2003, Ciantia and di Prisco, 2016).

In general, it should be point out that the soundness of the numerical analyses implementing simple constitutive models (MC and HB models) is conditioned by the two following assumptions:

1. all the stress points lie within the elastic domain, so that the distance from the failure envelope for each single point is a local indication of the safety margin;

2. when the stress point reaches the yield locus, the onset of a global failure mechanism could imply the overestimation of the strength capacity of the rock structure, since the real softening response is neglected. From this point of view, a numerical model providing only local plastic zones can instead be considered as acceptable. 
Assuming the simplified approach discussed above, the MC failure envelopes (Figure 10) of the calcarenite for different saturation degree are calibrated using laboratory tests results. Since the caves studied are daily used as a car parking for Cave A and historical visit for Cave B (hence prolonged flooded conditions can be excluded) hazard assessment is performed only for the STD process. In particular, the weathering scenario considered is an initially dry material $\left(f_{d r y}\right)$ that is gradually saturated $\left(f_{\text {STD }}\right)$ until a state of complete saturation is attained $\left(f_{\text {wet }}\right)$.

Once the constitutive model is calibrated and the simplifying assumptions are clearly stated, the the 3D FEM numerical analysis required for the hazard assessment of the cavity-building system can be performed (step\#5 in Figure 2). In Figure 11, 3D geometrical solids have been created from the laserscansions to describe the foundations system of the buildings and the volume of the cavities. A proper numerical domain has been considered in order to minimize the side effects on the numerical results considering an average distance of $10 \mathrm{~m}$ from the cave boundaries. The selected meshes (Figure 11b) is formed of 100000 and 400000-node-tetrahedric linear elements for Cave $A$ and Cave $B$ respectively. For the Cave $B$ the major discontinuities retrieved in the survey have been explicitly taken into account by modelling a solid interface (made of solid elements) where the strength parameter was reduced with respect to the massive calcarenite (cohesion reduced to $20 \%$ of the intact one, friction angle to $70 \%$ and dilatancy set to 0 ).

A preliminary series of analyses with quadratic elements (8 noded) with different mesh sizes are also performed to assess the influence of the mesh dependency of the numerical solution and define the best compromise in terms of computational time.

The construction stage procedure is composed of four stages for both Cave A and B:

1) a geostatic stress initialization referred to a free field condition, i.e. before both cave excavation and building construction, is assumed; the set of parameters prescribed for the calcarenite at this stage is equal to that corresponding to dry conditions (see Figure 10) and a value of $k_{0}$ equal to 0.5 is used following the in-situ investigations (step \#2);

2) the numerical simulation of the excavation is carried out by removing the elements in 10 load steps, following the actual excavation process based on historical reports. During such numerical stage, the development of plastic yielding in the rock mass surrounding the cave is carefully monitored to identify eventual failure mechanisms. This numerical analysis 
corresponds to a-posteriori assessment of the stability conditions of the rock mass during the excavation process;

3) the simulation of the building construction at ground surface is performed considering the exact sequence of building construction. In particular, only the pressure transmitted to the foundation has been considered for B1 and B3 buildings, whereas the complete soilstructure interaction system is simulated for B2. As for stage 2 , the eventual development of plastic mechanisms is verified to assess the stability of the cave system during construction.

4) the simulation of the in-situ weathering processes is finally performed by reducing the strength parameters of the calcarenite during saturation, as described in Figure 10. For this purpose, the strength and stiffness parameters of the rock domain are reduced from dry to wet (Figure 10), thus simulating the STD process. An overview of some stress components are shown in Figure 12b and Figure 12c in order to identify domain areas with a significant stress concentration, as well as plastic strains are monitored. Both for Cave A and B, the numerical results indicate that even for a completely saturated material $\left(f_{\text {wet }}\right)$ no failure mechanism develops, since only local plastic zones form at the base of some piles (see Figure $12 b$ for Cave A) or at the corners of the cave system (see Figure 12d for Cave B). For cave B only, an additional reduction of the yield surface is considered to simulate also the long term debonding process $\left(f_{L T D}\right)$. During the LTD experimental test, a strength reduction of $5 \%$ in 8 months was recorded. This process is simulated adopting the strength reduction method. After a strength reduction factor of 4 , corresponding to 10 year of constant water flux, the cave system is still not affected by a global failure mechanism. In fact plastic zones are only located in the lateral wall of cave B and no critical failure of the roof is recorded (Figure 12d). Finally, as shown in Figure 12e, the calculated displacements in this critical scenario generate a surface subsidence of few millimetres ( $\max$ value is $2.5 \mathrm{~mm}$ ) that does not induce any damage in the building B3.

Based on the results of the whole numerical process, the cave systems can be classified as safe, both under dry and wet conditions (step \# 6, hazard assessment). Nevertheless, the cave system should be kept as dry as possible by means of air ventilation and by preventing water infiltration. 


\subsection{Case study \#2: San Lazzaro cave (BO, Northern Italy)}

This case study is represented by an abandoned gypsum mine (Figure 13) in the village of San Lazzaro di Savena, close to Bologna (Italy). Here, mining was carried out until the end of the ' 80 s following the "room and pillar" method and the final cave system $\left(\approx 350.000 \mathrm{~m}^{3}\right)$ is organized according to three floors (Figure 14). During the mining operations, a karst cave was intercepted and karst water flowed into the mine $\left(\approx 80.000 \mathrm{~m}^{3}\right)$. As a consequence, the lower mining level was completely flooded and this condition has lasted up to the present due to the cave abandonment. Moreover, water circulation and infiltration from ground surface produced critical conditions prone to instability in several portions of the mining levels. In this context, buildings and infrastructures were constructed above the first and second level of the cave in the '70s and nowadays a large urbanized area around the Savena river is located downstream of the cave area, being at risk of flooding of a large volume of water.

Geomechanical properties of gypsum are known to change over time; in fact, water, or even air humidity, dissolve or weaken gypsum rock (Grgic et al. 2006). Therefore, the aim of the present study is the evaluation of the safety conditions of both the pillars and the cave roofs as well as the assessment of the effects of a possible collapse of the mine system on the buildings located at ground surface.

According to the methodology described in Section 2, a topographical survey by means of a total station, along with the analysis of existing maps, allowed to define the geo-referenced threedimensional system of the cave and the detailed geometry of the ground surface of the urbanized slope. Moreover, detailed geological surveys are carried out with the aim of identifying the major issues in place. In particular, the quarry is hosted in macrocristalline gypsum layers belonging to the Gessoso Solfifera Formation, overlaid by a silty clay layer, as shown in Figure 14b. The rock mass can be considered as massive, except for some areas, where some inclined joint sets, with large spacing, and the presence of karst phenomena are observed. A detailed geomechanical survey of the pillars is also carried out in order to acquire the parameters useful for the rock mass classification RMR (Bieniawski 1973), Q system (Barton et al. 1974) and GSI (Hoek 1977). The chemical analyses of the subsurface lake water indicate a conductivity of about $2100-2200 \mu \mathrm{S}$, a concentration of sulfates of $1350-1450 \mathrm{mg} / \mathrm{l}$ and an average temperature $\mathrm{T}$ of $9^{\circ} \mathrm{C}$. A large part of the shallower cave level is affected by rainfall water infiltrating from the ground surface and from the karst system: these phenomena are believed to increase over time due to the strong solubility of gypsum rock. 
As for the previous case, the conceptual model here adopted (Step \#2) is defined based on the insitu surveys. In particular, a 3-D continuum model is chosen based on the massive aspect of the rock mass and a FE model has been developed accordingly, as described in detail afterwards. Following the equivalent continuum approach (e.g. Hoek and Brown, 1997) the presence of large-spaced joints and discontinuities is taken into account by treating the rock mass as a continuum with reduced geomechanical properties.

First of all, a standard geomechanical characterization by UC, BT and TX tests on the fresh gypsum (Unweathered Rock - UR) was performed as shown in Figure 15. Then, in order to study the spatial effect of weathering, a series of UC and BT tests were performed on specimens taken at different drilling depths (70 m, Figure 14), at an average spacing of about $5 \mathrm{~m}$, with the value of the in-situ water content. The tests were performed on 8-cm diameter specimens enabling to define the whole failure envelope of the material with depth. Due to the experimental test results, the gypsum rock was classified into three levels of weathering: the portion above the $1^{\text {st }}$ level was indicated as fresh unweathered rock (UR), whereas the gypsum corresponding to the $1^{\text {st }}$ and $2^{\text {nd }}$ levels, since it was in prolonged contact with humid air, was named humid rock (HR). Finally, the gypsum surrounding the $3^{\text {rd }}$ level, being flooded by water, has been named as flooded rock (FR). UR gypsum is found to be characterized on average by a UCS strength of $12 \mathrm{MPa}$, a Young modulus E of $2.1 \mathrm{GPa}$ and it can be classified as EL according to Deere and Miller (1966). Figure 14b shows the boreholes dedicated to evaluate the weathering process. Nevertheless, in the same area more than 25 boreholes were already present and a large number of on site and laboratory investigations were performed during and after the mining activity. This guaranties the homogeneity assumption here considered.

In particular, Figure 16 summarizes the variation of UCS ( $\sigma_{c}$, Figure 16a), secant Young modulus $\left(E_{s}\right.$, Figure $16 \mathrm{~b})$ and tensile strength $\left(\sigma_{t}\right.$, Figure $16 \mathrm{c}$ ) as a function of depth. The UCS strengths of HR and FR are found to be respectively $20-30 \%$ and $50-60 \%$ less than the corresponding strength of UR. A similar trend is also found for the tensile strength reduction, whereas the same drop of stiffness $(\approx$ $65 \%$ ) is observed for both the HR and the FR. The dispersion of the data in Figure 15 and especially in Figure 16 is due to the size of the gypsum crystals (about $1 \mathrm{~cm}$ ), compared to the reduced diameter of the specimens (between 4 and $8 \mathrm{~cm}$ ) necessary to reproduce weathering in laboratory time. 
To corroborate the reduction of strength as an effect of flooding (FR), an additional series of UC tests was performed on smaller specimens $(D=24 \mathrm{~mm} ; \mathrm{H} / \mathrm{D}=2)$ immersed in situ in the $3^{\text {rd }}$ level water for different time lags. The results are reported in Figure 17a and show a marked reduction (up to $50 \%$ drop of the dry UCS) just after 15 days of immersion; after this initial reduction, no further drops are observed within one year of immersion. These results are consistent with the amount of strength reduction observed at the depth of the flooded level (Figure 16). Finally, a small-scale test showing the collapse of a pillar after 10 days in a water flux of $2 \mathrm{l} / \mathrm{h}$ is shown in Figure 17b; this test could be considered a further confirmation of the risk related to the pillar failure when an unsaturated water enters the cave system.

An elastic-perfectly plastic model with an HB failure criterion is adopted for the gypsum rock mass Figure 18a). The laboratory scale $(D=80 \mathrm{~mm})$ strength envelope for the intact rock (UR $R_{L A B}$ line in Figure 18b) is obtained by fitting the Mohr's circles at failure derived from the UC, BT and TX tests (Figure 18a). Size effects are then accounted for by using a Weibull distribution: the in-situ mass size larger than the critical size of $1 \mathrm{~m}$ (Castellanza et al. 2010) is accounted for by reducing the laboratory UCS strength of about 35\% (UR situ line in Figure 18b). To take the weathering process into account, a further strength reduction (equal to the UCS strength drop shown in Figure 16a) is used to comply with the $\mathrm{HR}_{\text {situ }}$ and $\mathrm{FR}_{\text {situ }}$ strength (see also Table 1 for the specific parameter of the $\mathrm{HB}$ failure loci referred to the in situ condition). Finally, the effect of the existence of a joint set in the rock mass (see step \#1) is accounted for by applying a reduced value of GSI=82 according to the suggestions proposed by Cai et al. (2004). The final strength envelopes considering all the effects

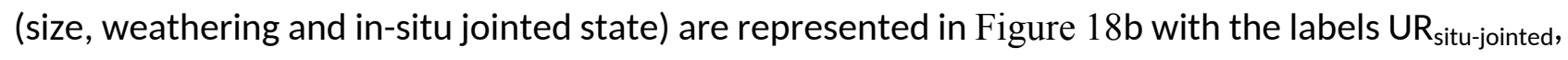
$\mathrm{HR}_{\text {situ-jointed }}$ and $\mathrm{FR}_{\text {situ-jointed }}$. The shallow silty clay layer is modelled using an elastic-perfectly plastic Mohr-Coulomb model.

At this point the 3D FE analyses are carried out in order to develop hazard assessment according to Step \#5 in Figure 2. As shown in Figure 19, detailed 3D geometrical solids have been created for the entire hill incorporating the mine system and the overlying building; an optimized discretization mesh, highly refined in the area of the cave system, is adopted. As for the previous case, the impact of mesh dependency on the numerical results is preliminary assessed by performing a series of elastic analyses with different mesh refinements.

As a preliminary assumption, the pillars are considered as the structures of the cave system most susceptible to failure and therefore hazard assessment is firstly focused on the evaluation of the 
safety margin of each pillar with respect to collapse; in fact, according to the Authors, the collapse of a single pillar would induce a process of sequential collapse of the adjacent pillars (pin failure mechanism), which in turn is likely to generate consequent failures of the chamber roofs and eventually give rise to a proper sinkhole phenomenon. Therefore, concerning the assessment of the safety margin of each pillar, two different methodologies have been followed. In the first, a simple $3 \mathrm{D}$ elastic analysis that does not require any construction stage is enough to evaluate the safety factor of each pillar with simplified approach; in the second, a fully non-linear analysis requiring a construction stage procedure is used to identify the most critical pillars.

Step \#5 - Methodology 1: according to Obert and Duvall (1967) approach, the safety factor of the general pillar, $i$, is firstly calculated as the ratio between the in-situ UCS strength of the pillar at the actual scale $\left(\sigma_{\text {lim,i }}\right)$ and the mean value of the in-situ axial stress existing in the same pillar $\left(\sigma_{\text {situ, }}\right)$. In particular, for the pillars located at the $1^{\text {st }}$ and $2^{\text {nd }}$ levels of the cave, the value of $\sigma_{\text {lim, },}$ is considered

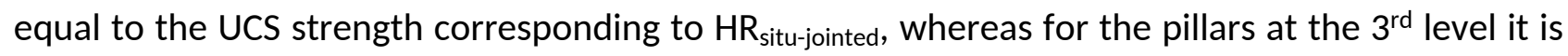

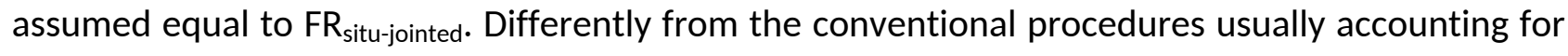
the loading area acting on the single pillar, the in-situ stresses $\sigma_{\text {situ,i }}$ of each pillar is evaluated based on the results of a 3D FEM elastic analysis. Figure 20 shows the resulting contours of the vertical stress in the pillars. For this calculation, the values of the tangent elastic modulus at $50 \%$ of the compressive strength, $\mathrm{E}_{50}$, are assumed and the $\sigma_{\text {situ, } i}$ are evaluated by averaging the vertical stresses calculated in the Gauss points in the mid-height section of the pillar. The values of the calculated safety factors are reported in the hazard map shown in Figure 21. Based on this approach, a large number of pillars of $3^{\text {rd }}$ level are in critical conditions $\left(1<F_{s}<1.1\right)$ while pillars at the $2^{\text {nd }}$ and $1^{\text {st }}$ levels (L1 and L2) result to be in safe conditions $\left(F_{s}>1.6\right)$ except for a single pillar (P7-1 - red area in Figure 21), located at the $1^{\text {st }}$ level $\left(F_{s}=1.15\right)$. It is worthwhile stressing that while critical pillars at the $3^{\text {rd }}$ level $\mathrm{L} 3$ have no buildings overlying at the ground surface, pillar P7-1 does.

Step \#5 - Methodology 2: in this case a series of non linear elasto-plastic 3D FEM analyses are carried out in order to simulate the actual conditions of the overall mine system. The above calibrated elastic-perfectly plastic constitutive model adopting the HB failure envelope for each class of weathered gypsum (UR, HR, FR; see step \#3) is used. The numerical analyses are performed according to the following construction stage procedure:

1) geostatic stress state is initialized before mine excavation and building construction, assuming homogeneous gypsum rock mass conditions, represented by $\mathrm{UR}_{\text {situ-jointed; }}$ 
2) mine excavation is simulated by removing groups of elements in accordance with the historical sequence of cave exploitation;

3) building construction is simulated by the application of equivalent pressure loads;

4) in situ weathering process at present is simulated by means of the reduction of the HB model parameters from $U R_{\text {situ-jointed }}$ to $\mathrm{HR}_{\text {situ-jointed }}$ for the gypsum of the $1^{\text {st }}$ and $2^{\text {nd }}$ levels and to $\mathrm{FR}_{\text {situ-jointed }}$ for the gypsum of the $3^{\text {rd }}$ level, as defined in Step \#3. Plastic strains $\varepsilon^{\mathrm{p}}$ developed only in some of the abandoned-mine pillars and contours of deviatoric plastic strains are shown in Figure 22. The numerical results in terms of the amount and distribution of deviatoric plastic strains confirms that: i) no global failure mechanism develops within the roofs as no $\varepsilon^{p}$ are recorded in such locations; ii) for the level $L 1, \varepsilon^{p}$ are concentrated in the pillars, so that they can be considered as one of the weakest structures of the whole system; iii) an amount of $\varepsilon^{\mathrm{p}}$ develops in pillar P7-1 of the $1^{\text {st }}$ level. This result suggests that the elastic analyses obtained with the Obert and Duvall (1967) approach presented above are reasonable.

5) A long term worst-scenario process is simulated by progressively removing the most critical pillars, starting from the removal of critical pillars in the $3^{\text {rd }}$ level L3, which is the one characterized by the minimum values of $F_{s}$, followed by progressively deactivating pillars and roofs, as shown in Figure 23. The worst-scenario concludes when a large number of pillars at the $3^{\text {rd }}$ level, along with the roof and the overlying pillars at the $2^{\text {nd }}$ level, are deactivated. The sequence of pillar removal is performed according to the following procedure: the pillar to be removed is the one closest to failure with relevant plastic strains and the minimum safety factor evaluated with Obert and Duvall (1967) approach; whenever a pillar is removed the load acting on the removed pillar is transferred to the surrounding pillars and therefore the values of the Fs for the active pillars are updated always with Obert and Duvall (1967) approach. According to this procedure, the implicit drawback represented by neglecting the brittle behaviour and the crack propagation associated with the observed post-failure fragile response of gypsum is reduced. As shown in Figure 23, this procedure allows to define a subsidence basin of $30000 \mathrm{~m}^{2}$ at ground surface that do not significantly affect any building. In this perspective, the performed 3D numerical analysis is capable of describing a very critical scenario and should be considered as a tool for predicting the negative consequences in terms of subsidence. These results were used to design a currently ongoing monitoring 
campaign and to decide not to undertake any remediation measure to prevent settlement damage to buildings (Ciantia et al. 2018).

6) An additional catastrophic scenario adopting 3D CFD analyses were used to evaluate the amount of water that could be eventually ejected outside the mine and eventually flooding the downstream village. It was decided to consider a further unfavourable condition which is the simultaneous collapse of the entire roof of Level 3 to maximize the impact of the falling down gypsum mass on the volume of water present in mine. The results are shown for different time intervals in Figure 24. It could be shown that the analyses revealed the internal buffering capacity of the intact portion of Level 2. Furthermore, the analyses allowed to assess the volume and the velocity of the water that can flood out from Level 1 towards the urbanized area. The estimated volume of the flooding water is about $2000 \mathrm{~m}^{3}$. It represents approximately the $2 \%$ of the water that flood the mine. This amount is compatible with small channelling works to bring this water in the Savena River located just outside the mine. The forecasting of flooding water revealed again a low risk for the urbanized area. The technical details can be found in Castellanza et al 2015.

As regards step \#6 of the methodology (i.e. hazard assessment), some important considerations arise based on the previously described results for this specific case study: i) the most critical part of the cave system is represented by the $3^{\text {rd }}$ level $\mathrm{L} 3$ where a large number of pillars result to be in critical conditions; ii) assuming a catastrophic scenario of sequential pillar collapse, the consequent subsidence basin and the amount of flooding water does not significantly affect the existing buildings; iii) to increase the safety conditions, some structural reinforcements of the existing most critical pillars should be considered. For flooded level 3, the proposed remediation measure consists of reducing the inflow of fresh water, avoiding further dissolution as the current concentration of the solute mass is at maximum. With respect to the initial idea to fill the entire level 3 with a fluidized cemented soil as in Castellanza et al. (2010), the final cost of the proposed countermeasures is less than one order of magnitude of the initial one. It means that a small investment in the proposed methodological approach including experiments and theoretical and numerical predictions produce a large amount of money saved.

\section{Conclusions}

The paper describes a methodological approach for hazard assessment of underground caves within soft rock masses affected by weathering, based on a step-by-step procedure that includes in-situ 
surveys, laboratory experimental studies, theoretical analyses and finally numerical investigations. The procedure aims to evaluate the physical variables on which depend the variation of strength and stiffness of the cave rock up to failure, so that efficient remediation measures can be adequately defined. When the primary cause of instability is rock mechanical weakening evolving with time, as triggered by water, humidity or chemical weathering, safety conditions of the underground cave are observed to reduce with time, even if loading conditions are maintained constant with time. To derive reliable assessments of the cave stability conditions, the methodological approach is applied to three complex case histories, two of which considering underground cave systems in calcarenite formations and one referring to an abandoned gypsum mine. The results suggest that:

- A detailed rock characterization, carried out through laboratory and field investigations, is fundamental in order to identify the susceptibility of the examined rock to environmental weathering, and hence should be planned as first.

- A three-dimensional elasto-plastic finite element model implementing the current state of the rock mass and the eventual interaction with overlying structures needs to be carried out in order to evaluate the initial safety condition of the considered system.

- To evaluate how safety conditions change in time due to weathering, the same numerical model should be framed in order to assess future scenarios of the cave stability based on the time evolution of weathering process. To do so, the rock characterization tests previously developed should include some sort of tests replicating possible weathering scenarios at laboratory scale.

- This methodological approach could be enriched by introducing the effect of rock brittleness in the acceleration of the rock failure process. This requires to improve the numerical code by including time-dependent coupled hydro-chemo-mechanical constitutive models, combined with crack propagation algorithms to describe joint behaviour.

\section{Acknoledgements}

The authors wish to thank Professor Claudio di Prisco and Dr. Geol. Gianmarco Orlandi for many fruitful discussions. In particular, they are grateful to Prof. Roberto Nova for his passion and enthusiasm devoted to scientific investigation. The Municipality of San Lazzaro di Savena (BO) and Mrs. Papagna, owner of the calcarenite mine in Canosa (BT), are also gratefully acknowledged. 
628 - Aliguer, I., Carol, I., Alonso, E.E. (2013). Numerical analysis and safety evaluation of a large arch dam 629 founded on fractured rock, using zero-thickness interface elements and a c- $\varphi$ reduction method, $630 \quad$ COMPLAS XI,1233-1243.

631 - Andriani G.F., Walsh N. (2007). The effects of wetting and drying, and marine salt crystallization on 632 calcarenite rocks used as building material in historic monuments, Geological Society, London, Special 633 Publications, vol. 271, 179-188.

634 - Auvray C., Homand F., Sorgi C. (2004). The aging of gypsum in underground mines. Engineering 635 Geology, 74, $183-196$.

636 - Barton, N., Lien, R., Lunde, J. (1974).Engineering classification of rock masses for the design of tunnel 637 support. Rock Mechanics. 6: 4, 189-236.

638 - Bekendam R.L. (1998). Pillar stability and large-scale collapse of abandoned room and pillar limestone 639 mines in South-Limburg, the Netherlands. PhD Thesis, Delft University of Technology, the Netherlands.

640 - Bètournay M.C. (2009). Abandoned Metal Mine Stability Risk Evaluation. Risk Analysis, Vol. 29, No. 10, 641 1355-1370. DOI: 10.1111/j.1539-6924.2009.01267.x

642 - Betti D., Buscarnera G., Castellanza R., Nova R. (2008). Numerical analysis of the life-time of an 643 abandoned gypsum mine, Proc. 12th International Conference IACMAG 2008, Goa (India), Oct. 2008, $644 \quad 1210-1218$.

645 - Betti D., Castellanza R., (2008) La modellazione 3D a elementi finiti di opere in sotterraneo, Strade e $646 \quad$ Autostrade, 1, 2008, 148-150.

647 - Bieniawski, Z.T. (1976). Rock mass classifications in rock engineering. Proc. Symposium on Exploration 648 for Rock Engineering. Balkema, Rotterdam, 97- 106.

649 - Brown, E. T., Bray, J. W., Ladanyi, B., and Hoek, E. (1983). "Ground response curves for rock tunnels." J. 650 Geotech. Engrg., ASCE, 109(1), 15-39.

651 - Cai M, Kaiser PK, Uno H, Tasaka Y, Minami M (2004). Estimation of rock mass deformation modulus 652 and strength of jointed hard rock masses using the GSI system. Int J Rock Mech Min Sci 41,3-19.

653 - Carranza-Torres, C., and Fairhurst, C. (1999). General formulation of the elasto-plastic response of 654 openings in rock using the Hoek-Brown failure criterion. Int. J. Rock Mech. Min. Sci., 36 (6), 777-809.

655 - Carter, T.G. (1992). A new approach to Surface Crown Pillar Design. Proc. 16th Can. Rock Mechanics 656 Symposium, Sudbury, 75-83.

657 - Castellanza R., Betti, D, Lambrughi (2009). Modellazione 3D dello scavo con TBM di tunnel in area 658 urbana, Gallerie $2 \cdot 2009,45-56$.

659 - Castellanza R., Gerolymatou E., and Nova R. (2008). An Attempt to Predict the Failure Time of 660 Abandoned Mine Pillars, Rock Mechanics \& Rock Engineering, 41 (3), 377-401, ISSN 0723-2632. 
- Castellanza R., Nova R. (2004). Oedometric Tests on Artificially Weathered Carbonatic Soft Rocks, 662 Journal of Geotechnical and Geoenvironmental Engineering ASCE, 130, 7, 728-739.

663 - Castellanza R., Nova R., Orlandi G. (2010). Flooded gypsum mine remedial by chamber filling, Journal of 664 Geotechnical and Geoenvironmental Engineering ASCE Vol. 136(4), pp. 629-639, DOI: 10.1061• ASCE 665 GT.1943-5606.0000249.

666 - Castellanza, R., Orlandi, G. M., Di Prisco, C., Frigerio, G., Flessati, L., Fernandez-Merodo, J. F., Crosta, G. 667 (2015). 3D numerical analyses for the quantitative risk assessment of subsidence and water flood due 668 to the partial collapse of an abandoned gypsum mine. In IOP Conference Series: Earth and

670 - Ciantia, M. O., Hueckel, T. (2013). Weathering of submerged stressed calcarenites: chemo-mechanical 671 coupling mechanisms, Géotechnique, 63, No. 9, 768-785.

672 - Ciantia, M.O., Castellanza, R., Crosta, G.B. and Hueckel, T., (2015). Effects of mineral suspension and 673 dissolution on strength and compressibility of soft carbonate rocks. Engineering Geology,184, 1-18.

674 - Ciantia, M.O., Castellanza, R. and Di Prisco, C., (2014). Experimental study on the water-induced 675 weakening of calcarenites. Rock Mechanics and Rock Engineering, 48(2), p 441-461.

676 - Ciantia, M.O. and Prisco, C., (2016). Extension of plasticity theory to debonding, grain dissolution, and 677 chemical damage of calcarenites. International Journal for Numerical and Analytical Methods in 678 Geomechanics,40(3), 315-343.

679 - Ciantia, M. O., Castellanza, R., di Prisco, C., (2013). Chemo-mechanical weathering of calcarenites: 680 Experiments and theory. In Coupled Phenomena in Environmental Geotechnics (ads Manassero et al), $681 \quad 541-548$.

682 - Ciantia, M. O., Castellanza, R., di Prisco, C., Hueckel, T. (2012). Experimental methodology for chemo683 mechanical weathering of calcarenites. In Multiphysical testing of soils and shales (eds L. Laloui and A. 684 Ferrari), 331-336.

685 - Ciantia, M. O., Castellanza, R. (2016). Modelling weathering effects on the mechanical behaviour of 686 rocks. European Journal of Environmental and Civil Engineering, 20(9), 1054-1082.

687 - Ciantia, M. O., Castellanza, R., Fernandez-Merodo, J. A. (2018). A 3D Numerical Approach to Assess the 688 Temporal Evolution of Settlement Damage to Buildings on Cavities Subject to Weathering. Rock 689 Mechanics and Rock Engineering, 1-24, https://doi.org/10.1007/s00603-018-1468-3, ISSN 1434-453X.

690 - Deere D. and Miller R.D. (1966). Engineering classification and index properties for intact rock. Univ. of 691 Illinois, Tech. Rept. No. AFWL-TR-65-116.

692 - Detournay E., Fairhurst C. (1987). Two-dimensional elastoplastic analysis of a long, cylindrical cavity 693 under non-hydrostatic loading. Int. J. Rock Mechanics Min. Sci., 24(4), 197-211.

694 - Diederichs, M.S., (2003). Rock fracture and collapse under low confinement conditions. Rock Mech. 695 Rock Engng., 36 (5), 339-381. 
- Diederichs, MS. and Kaiser, PK. (1999).Tensile strength and abutment relaxation as failure control mechanisms in underground excavations. Int. Journal of Rock Mechanics and Mining Science, 36: 1, 6996.

- $\quad$ Fazio N.L., Perrotti M., Lollino P., Parise M., Vattano M., Madonia G., Di maggio C. (2017). A threedimensional back-analysis of the collapse of an underground cavity in soft rocks. Engineering Geology, $228,301-311$.

- $\quad$ Fenton, G. A., Griffiths, D. V. (2008). Risk assessment in geotechnical engineering (Vol. 461). New York: John Wiley \& Sons.

- Fernandez-Merodo J. A., Castellanza R., Mabssout M., Pastor M., Nova R., Parma M. (2007). Coupling transport of chemical species and damage of bonded geomaterials Computers and Geotechnics, vol. 34 , issue $4,200-215$.

- Ferrero A.M., Segalini A., Giani G.P. (2010). Stability analysis of historic underground quarries. Computers \& Geotechnics, 37, 476-486.Gerolymatou E., Castellanza R., Nova R. \& Vardoulakis I. (2009). The weathering of the foundation of the Tholos of Asklepios at Epidaurus: experiments and modelling. Proc. of the 1st Int. Symposium on Computational Geomechanics (ComGeo I), Juan-les-Pins, Cote d'Azur, France, April 29 - May 1st, 2009.

- Fiore A., Fazio N.L., Lollino P., Luisi M., Miccoli M.N., Pagliarulo R., Perrotti M., Pisano L., Spalluto L., Vennari C., Vessia G., Parise M. (2018). Evaluating the susceptibility to anthropogenic sinkholes in Apulian calcarenites, southern Italy. Advances in karst research: theory, fieldwork and applications, Geological Society, London, Special Publications, 466, Parise at el. (Eds).

- Gesualdo A., Minutolo V., Nunziante L. (2001). Local collapse in soft rock bank cavities. ASCE Journal of Geotech. and Geoenv. Engng., 127(12), 1037 - 1041.

- Ghabezloo S., Pouya A. (2006). Numerical modelling of the effect of weathering on the progressive failure of underground limestone mines. Eurock 2006, Multiphysics Coupling and Long Term Behaviour in Rock Mechanics: Proc. of the Int. Symp. ISRM, Eurock 2006, Liège, Belgium.

- Goodings D.J., Abdulla W.A. (2002). Stability charts for predicting sinkholes in weakly cemented sand over karst limestone. Engineering Geology, 65, 179 - 184.

- Gong, W., Juang, C. H., Martin, J. R., Tang, H., Wang, Q., Huang, H., (2018). Probabilistic analysis of tunnel longitudinal performance based upon conditional random field simulation of soil properties. Tunnelling and Underground Space Technology, 73, 1-14.

- Grgic D., Homand F., Giraud A. (2006). Modelling of the drying and flooding of underground iron mines in Lorraine (France). International Journal of Rock Mechanics \& Mining Sciences, 43 (2006), 388-407.

- Griffiths, D. V. , Lane, P. A. (1999). Slope stability analysis by finite elements, Géotechnique, 49, No. 3 , 378-403.

- Griffiths, D. V., Fenton, G. A. (2004). Probabilistic slope stability analysis by finite elements. Journal of Geotechnical and Geoenvironmental Engineering, 130(5), 507-518.

- GTS-NX (2010) Geotechnical and Tunnel Analysis System - User's Guide (www.midasuser.com) 
- Hoek, E. (1989). A limit equilibrium analysis of surface crown pillar stability. In Surface crown pillar evaluation for active and abandoned metal mines, (ed. M.C. Betourney), 3-13. Ottawa: Dept. Energy, Mines \& Resources Canada.

- Hoek, E., Brown, E. T. (1997). Practical estimates of rock mass strength. International Journal of Rock Mechanics and Mining Sciences, 34(8), 1165-1186.

- Jaeger, J.C., Cook, N.G.W. (1969). Fundamentals of Rock Mechanics . London: Chapman and Hall 593pp.

- $\quad$ Jiang Q., Feng X., Fan Y., Fan Q., Liu G., Pei S. (2017). In situ experimental investigation of basalt spalling in a large underground powerhouse cavern. Tunnelling and underground space technology, $68,82-94$.

- Lagioia R, Nova R (1995). An experimental and theoretical study of the behaviour of a calcarenite in triaxial compression. Géotechnique, 45(4): 633-648.

- Lollino, P., Andriani, G. F. (2017). Role of brittle behaviour of soft calcarenites under low confinement: laboratory observations and numerical investigation. Rock Mechanics and Rock Engineering, 50(7), 1863-1882.

- $\quad$ Li L.H., Yang Z.F., Yue Z., Zhang L.Q. (2009). Engineering geological characteristics, failure modes and protective measures of Longyou rock caverns of 2000 years old. Tunnelling and Underground Space Technology 24 (2009) 190-207.

- $\quad$ Lippmann H. (1971). Plasticity in rock mechanics. Int. J. Mech Sci., 13, 291 - 297.

- Mortazavi A., Hassani F.P., Shabani M. (2009). A numerical investigation of rock pillar failure mechanism in underground openings. Computers and Geotechnics, 36, 691-697.

- $\quad$ NAFEMS (1983), International Association for the Engineering Modelling, Analysis and Simulation Community (www.nafems.org)

- Nickson, S.D. (1992). Cable support guidelines for underground hard rock mine operations. MSc thesis, University of British Columbia, Vancouver.

- Nova R., Castellanza R., Tamagnini C. (2003). A constitutive model for bonded geomaterials subject to mechanical and/or chemical degradation. Int. J. Num. Anal. Meth. Geomech., 27(9): 705-732.

- Obert, L., Duvall, W.I. (1967). Rock Mechanics and the Design of Structures in Rock . New York: Wiley. 65 pages.

- Panet, M. (1995). Le calcul des tunnels par la méthode convergence-confinement. Presses de l'école nationale des Ponts et chaussées, Paris.

- Parise, M., Lollino, P. (2011). A preliminary analysis of failure mechanisms in karst and man-made underground caves in Southern Italy. Geomorphology 134, 132-143.

- Pelizza S., Oreste P.P., Peila D., Oggeri C. (2000). Stability analysis of a large cavern in Italy for quarrying explotiation of a pink marble. Tunnelling and underground space technology, 15 (4), 421 - 435. 
- Polimeno, A. (2007). Il crollo di via Firenze in Gallipoli. I'intervento dei vigili del fuoco, Geologi e Territorio, 4-2006/1-2007, 13-19 (in Italian)

- Potvin, Y., Milne, D. (1992). Empirical cable bolt support design. Proc. of Int. Symposium on Rock Mechanics, Sudbury, ON, Canada.

- Ribacchi R., Riccioni R. (1977). Stato di sforzo e di deformazione intorno ad una galleria circolare. Gallerie, 4, 7 - 18 (in Italian).

- $\quad$ Wang, S.Y., Sloan S.W., Huang M.L., Tang C.A. (2011). Numerical Study of Failure Mechanism of Serial and Parallel Rock Pillars. Rock Mechanics and Rock Engineering, 44, 179 - 198.

- Weibull W. (1939). The phenomenon of rupture in solids. IngvetenskAkad. Handl. No. 153.

- Yang Z., Yue Z., Li L. (2011). Design, construction and mechanical behavior of relics of complete large Longyou rock caverns carved in argillaceous siltstone ground. Journal of Rock Mechanics and Geotechnical Engineering. 2011, 3 (2): 131-152.

780 - Tamagnini, C., Ciantia, M.O., (2016). Plasticity with generalized hardening: constitutive modeling and 781 computational aspects. Acta Geotechnica, pp.1-29.

- Trinh N., Jonsson K. (2013). Design considerations for an underground room in a hard rock subjected to a high horizontal stress field at Rana Gruber, Norway. Tunnelling and underground space technology, 38, $205-212$.

- Van Den Eeckhaut, M., Poesen, J., Dusar, M., Martens, V., Duchateau, P. (2007). Sinkhole formation above underground limestone quarries: A case study in South Limburg (Belgium). Geomorphology, 91(1), 19-37.

- Vattano M., Di Maggio C., Madonia G., Parise M., Lollino P., Bonamini M. (2013). Examples of anthropogenic sinkholes in Sicily and comparison with similar phenomena in Southern Italy. Proc. 13th Multidisciplinary Conference on Sinkholes and the Engineering and Environmental Impacts of Karst, Carlsbad, New Mexico (USA), Land L., Doctor D.H., Stephenson J.B. (Eds.), 263 - 271.

- Zhang Q.B., He L., Zhu W.S. (2016). Displacement measurement techniques and numerical verification in $3 \mathrm{D}$ geomechanical model tests of an underground cavern group. Tunnelling and underground space technology, 56, $54-64$. 


\section{List of figure caption}

797 Figure 1. Environmental weathering and cave instability

Figure 2. Flow chart of the methodological approach

Figure 3: Evolution of safety factor with time

Figure 4: Step \#1 - (a) Picture of the in-situ survey for Cave A and B; (b) Plan of the existing buildings superimposed to the planar extension of the caves (red points are the locations of the sampling cores; (c) 3D laser-scan reconstruction of the caves including some part of the buildings.

Figure 5: Step \#3 - in situ drilling (left) and laboratory re-drilling for sample preparation (right)

Figure 6: Step \#3 - (a) micromechanical investigations: SEM analyses, thin section, and schematic reconstruction; (b) environmental weathering mechanism for calcarenite: short term weathering STD and long term weathering (LTD).

Figure 7: Step \#3- Experimental results: STD laboratory weathering by uniaxial test (UCS) and indirect tensile test (BT): (a) axial stress - strain curves at different saturation degree; (b) UCS ad BT strength vs. saturation degree

Figure 8: Step \#3- Experimental results: in situ UCS strength and Young modulus vs. distance from cave boundary surface

Figure 9: Step \#4- (a) Advanced constitutive model: Yield surfaces at different saturation degree process (STD) and dissolved mass (LTD) process (Nova et al. 2003); (b) Simplified constitutive model: Failure loci for MC and HB model referred to the $f_{\text {wet }}$.

Figure 10: Step \#4- Adopted constitutive model simulating the STD weathering process.

Figure 11: Step \#5- Geometrical and numerical model : a) Cave A; b) Cave B with an hidden part of the mesh

Figure 12: Step \#5-Numerical results (contours) - Cave A: (a) shear stresses; (b) plastic strains; Cave B: (c) maximum principal stresses (compression are negative) (d) plastic strains after a total saturation $\left(f_{\text {wet }}: S_{r}=1\right)$ and after a LTD process $\left(f_{L T D}\right)$ that correspond to a Strength Reduction Factor of 4,28 ; e) vertical displacement at $S_{r}=1$.

Figure 13: Step \#1- preliminary survey for San Lazzaro cave.

Figure 14: Step \#1- Planar view (a) and section (b) of the abandoned mine system interacting with buildings.

Figure 15: Step \#3- Experimental results for fresh gypsum (UR): UC (Uniaxial Compression), BT (Indirect Tensile Test) and TX test (multistage triaxial test).

Figure 16: Step \#3- Experimental results: in situ existing weathering profile of compression strength, stiffness and tensile strength.

Figure 17: Step \#3- Experimental results: (a) Decay resistance to uniaxial specimens immersed in situ (in the flooded quarry at Level L3); (b) Small-scale simulation of collapse of a pillar in a water flux.

Figure 18: Step \#4- Failure envelopes adopted for the gypsum: (a) fitting with HB and MC criterion; (b) Hoek and Brown failure loci for the in situ weathered gypsum;

Figure 19: Step \#5- Geometrical model and discretization mesh. a) Perspective view and top view of the solids; b) perspective view of the finite element mesh and detail of the mesh in the cave system.

Figure 20: Step \#5 - Metodology 1 - Elastic analysis : Contour of the in situ vertical stress state of pillars evaluated by 3D FEM analyses; in the right bottom corner an example of the vertical stress diagram used to evaluate the average value of $\sigma_{\text {situ }}$ is shown. 
836 Figure 21: Step \#5 - Metodology 1 : Pillar safety factor evaluated by combining the in situ stress level and 837 rock strength

838 Figure 22: Step \#5 - methodology 2 -Numerical results: plastic strains at the present conditions

839 Figure 23: Step \#5: Evaluation of subsidence basin after removing the critical pillar and roof of level L3: 840 Contour of plastic strain at section AA (left), contour of superficial subsidence (right)

841 Figure 24: Step \#5 Forecast of the outgoing volume of water from level 1 in case of quick collapse of the 842 entire roof of level L3

\section{TABLE}

844 Table 1: Hoek and Brown (1997) failure criteria parameters for in situ condition without joints for the

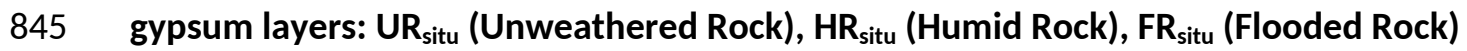

846 


\section{Figure}

2 (please note that all the picture could be fit in one semicolon; here the picture are 3 enlarged to facilitate the review process)

4

Figure 1. Environmental weathering and cave instability

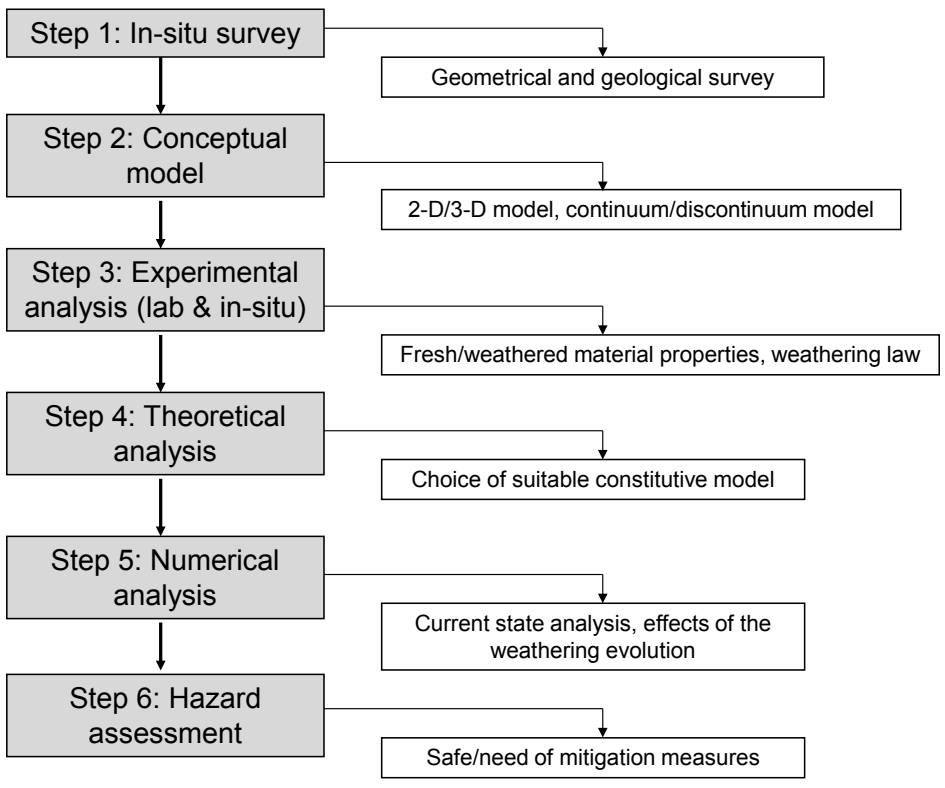

Figure 2. Flow chart of the methodological approach 


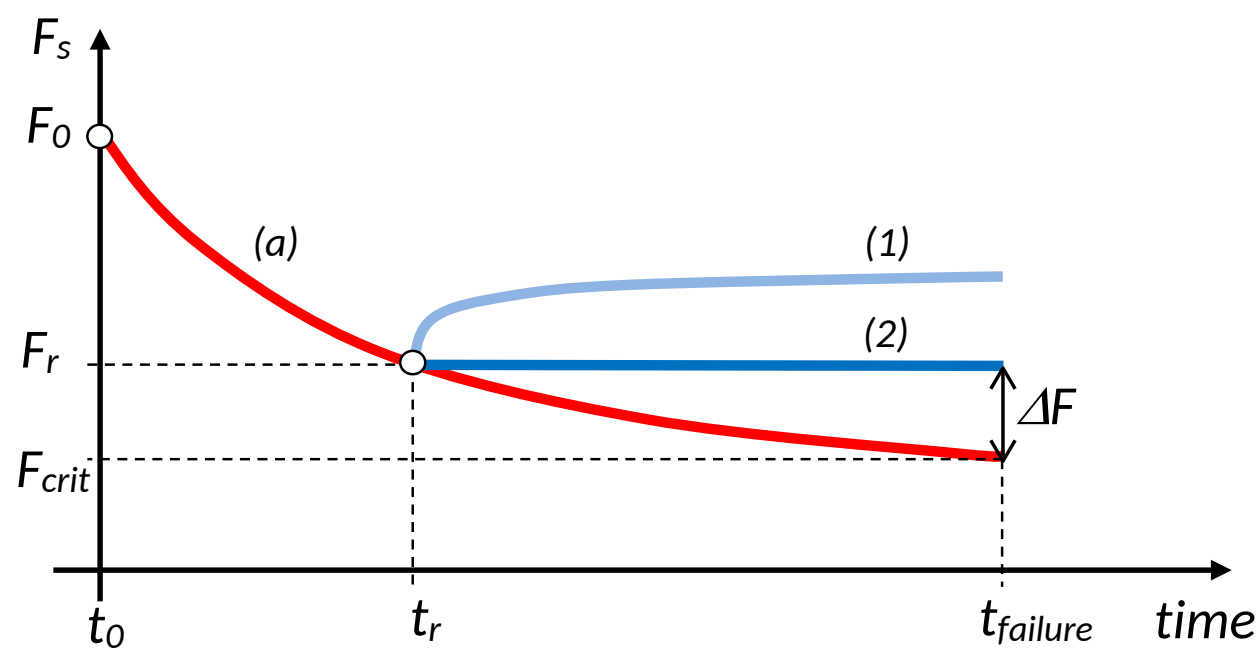

Figure 3: Evolution of safety factor with time 

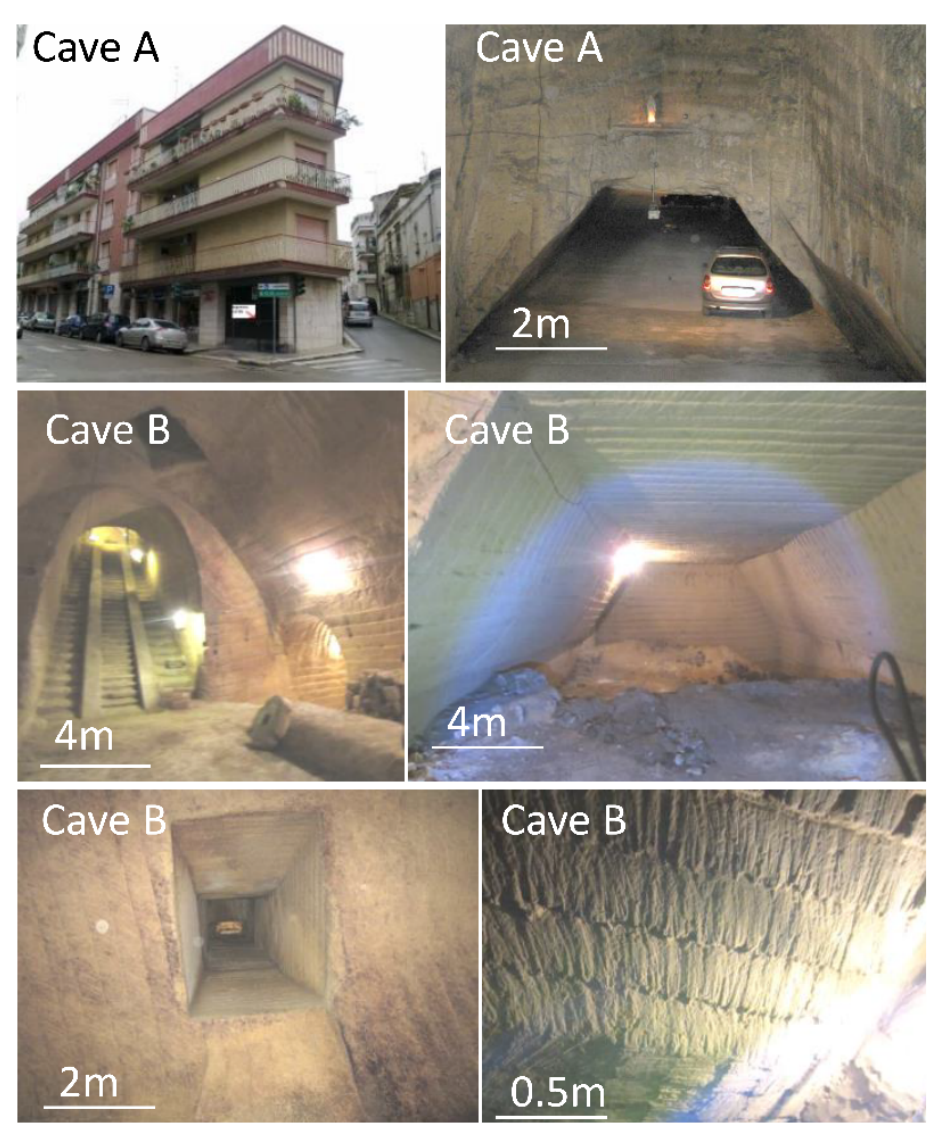

a)

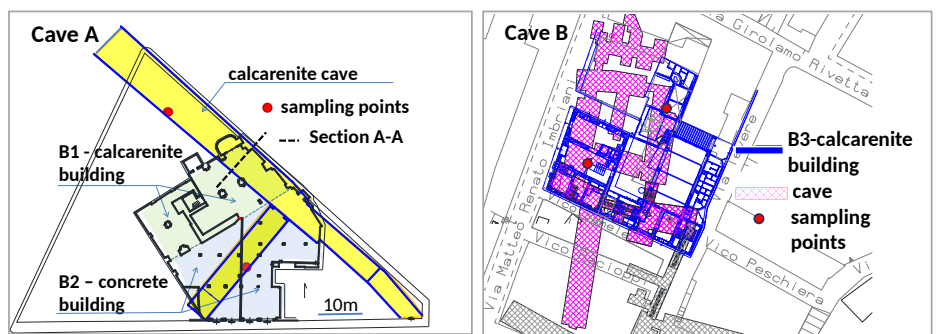

b)

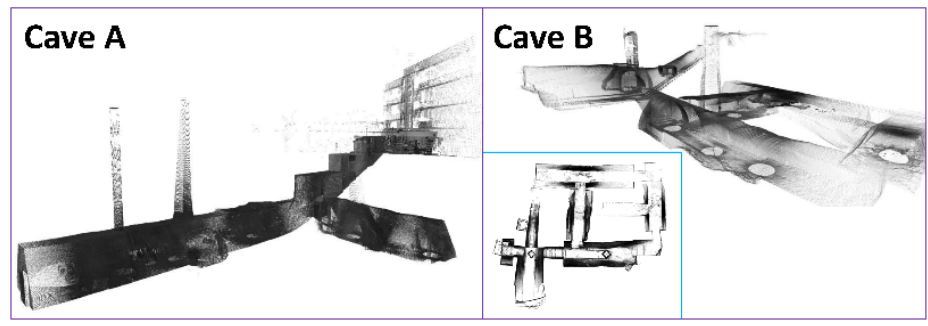

c)

Figure 4: Step \#1 - (a) Picture of the in-situ survey for Cave A and B; (b) Plan of the existing buildings superimposed to the planar extension of the caves (red points are the locations of the sampling cores; (c) 3D laser-scan reconstruction of the caves including some part of the buildings. 


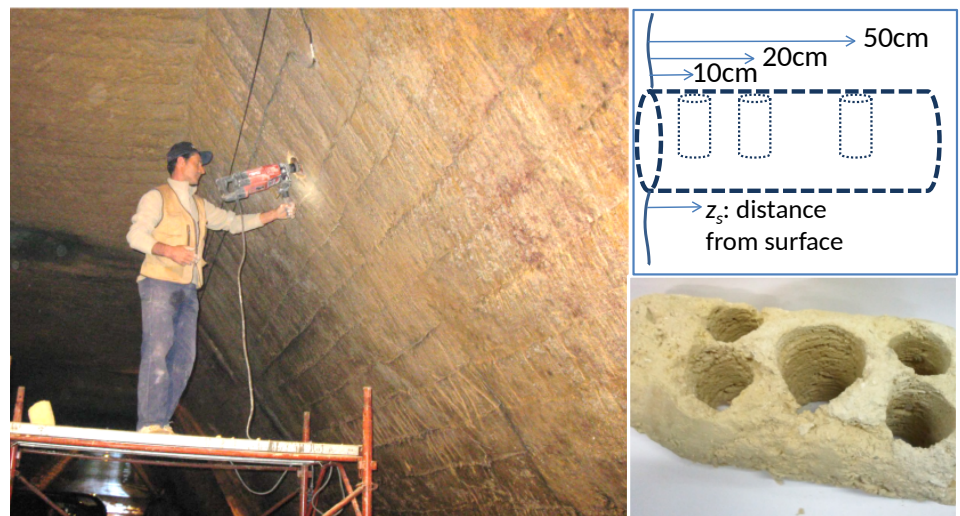

Figure 5: Step \#3 - in situ drilling (left) and laboratory re-drilling for sample preparation (right)

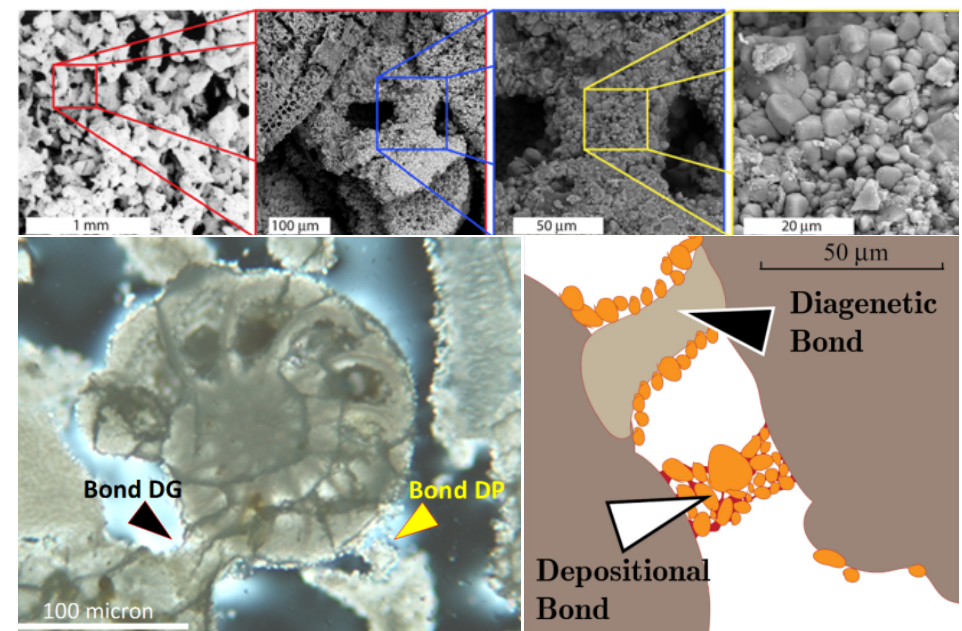

a)

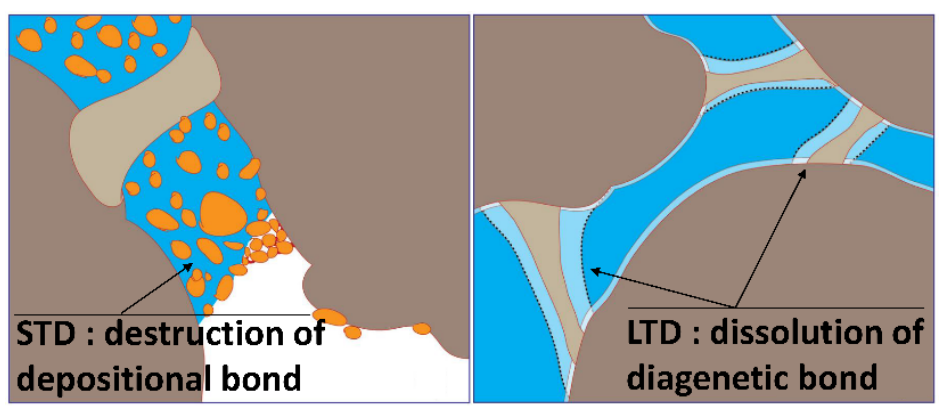

b)

Figure 6: Step \#3 - (a) micromechanical investigations: SEM analyses, thin section, and schematic reconstruction; (b) environmental weathering mechanism for calcarenite: short term weathering STD and long term weathering (LTD). 


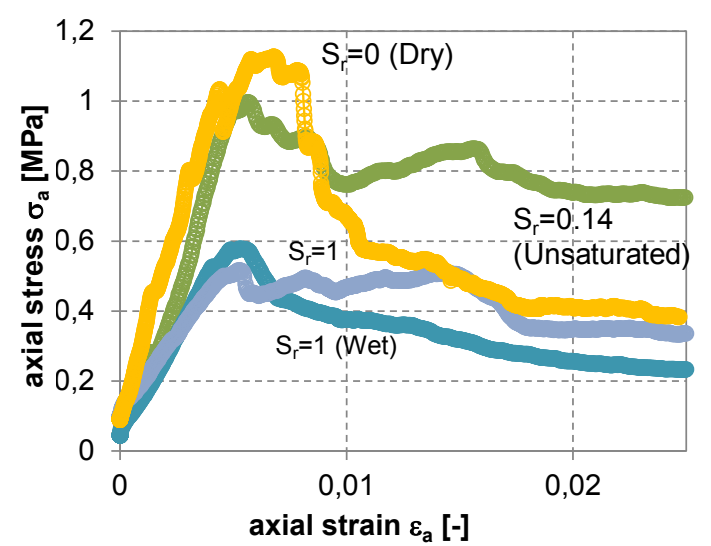

a)

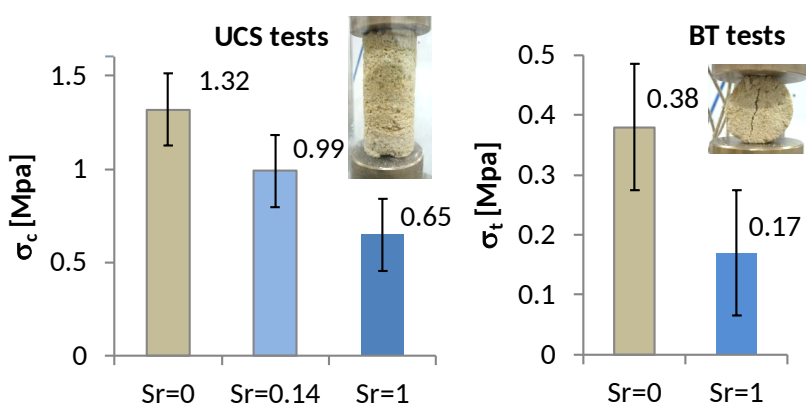

b)

Figure 7: Step \#3- Experimental results: STD laboratory weathering by uniaxial test (UCS) and indirect tensile test (BT): (a) axial stress - strain curves at different saturation degree; (b) UCS ad BT strength vs. saturation degree

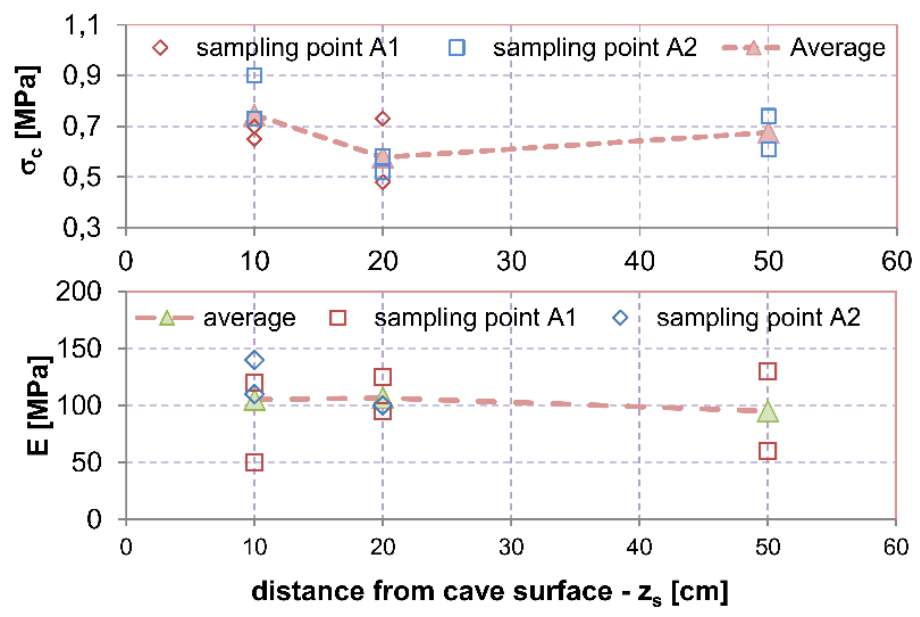
Figure 8: Step \#3- Experimental results: in situ UCS strength and Young modulus vs. distance from cave
boundary surface 


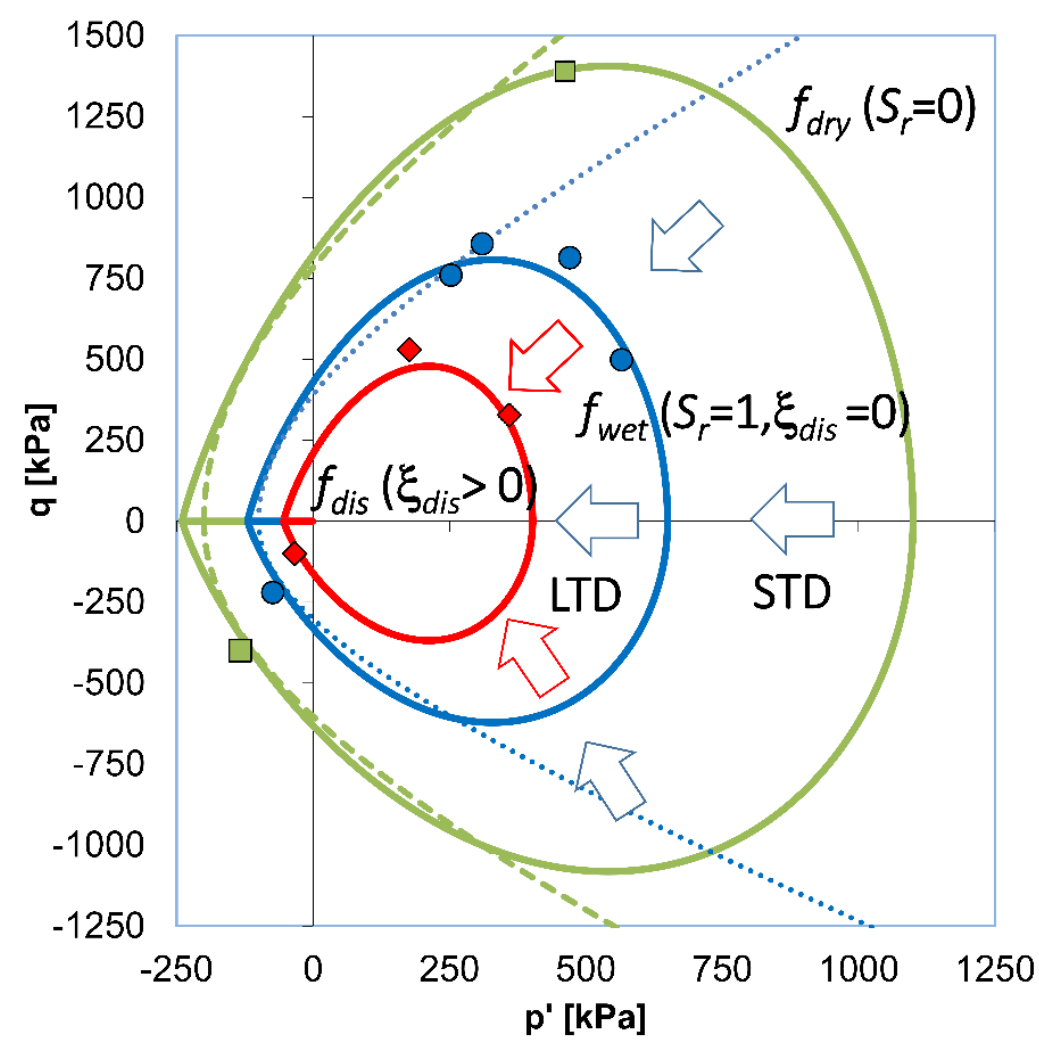

44

45 a)

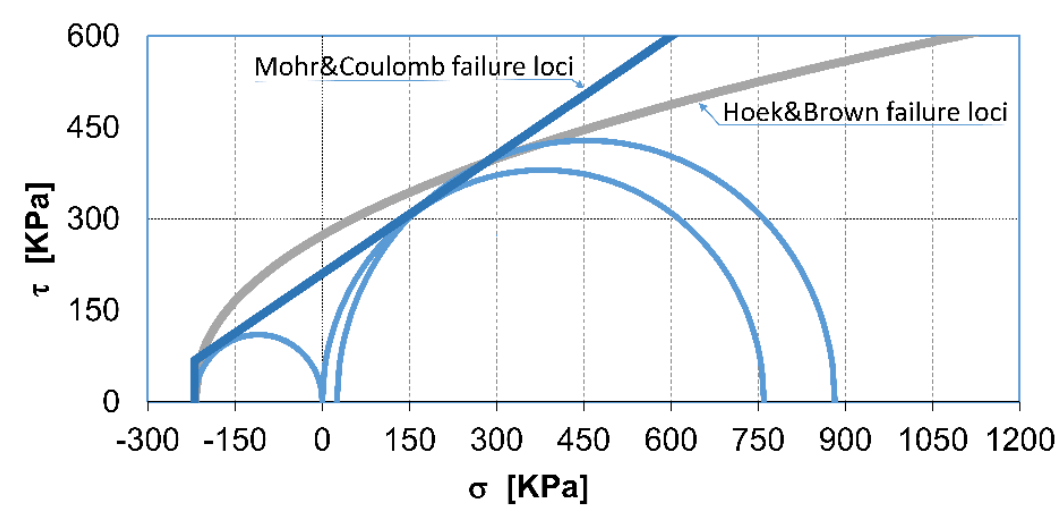

b)

Figure 9: Step \#4- (a) Advanced constitutive model: Yield surfaces at different saturation degree process (STD) and dissolved mass (LTD) process (Nova et al. 2003); (b) Simplified constitutive model: Failure loci for MC and HB model referred to the $f_{\text {wet }}$. 


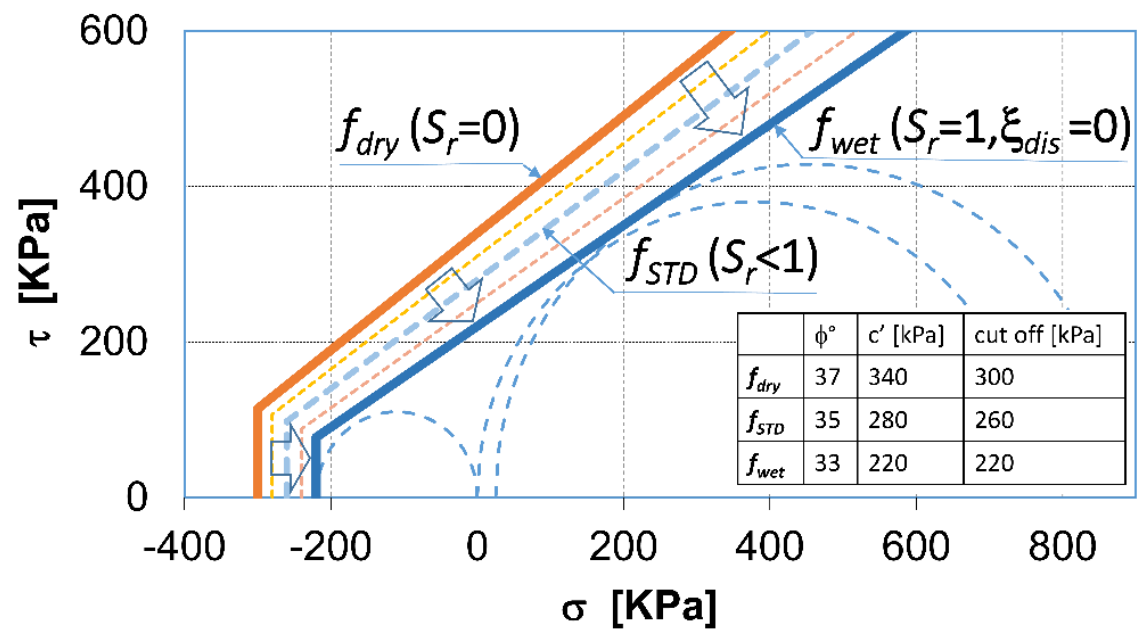

Figure 10: Step \#4- Adopted constitutive model simulating the STD weathering process.
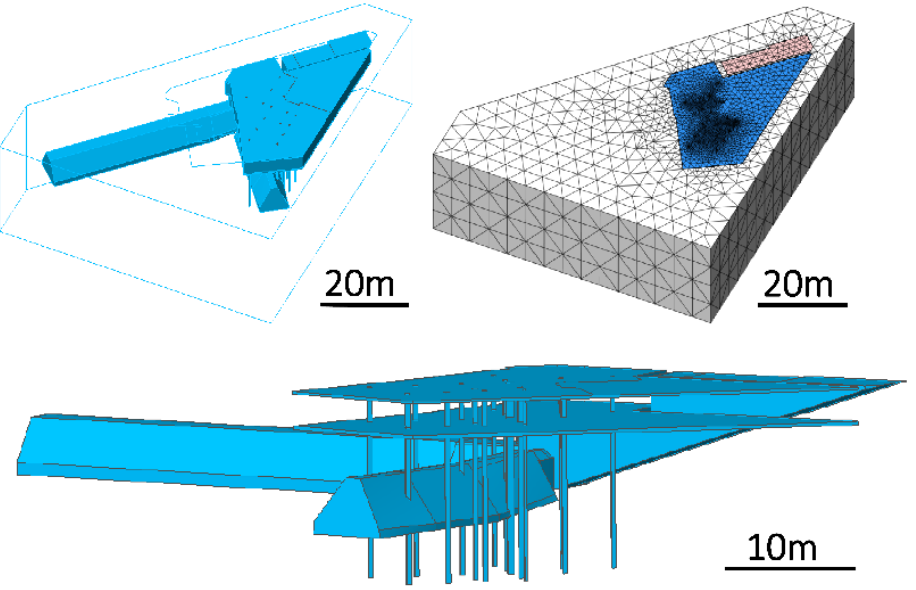

a)

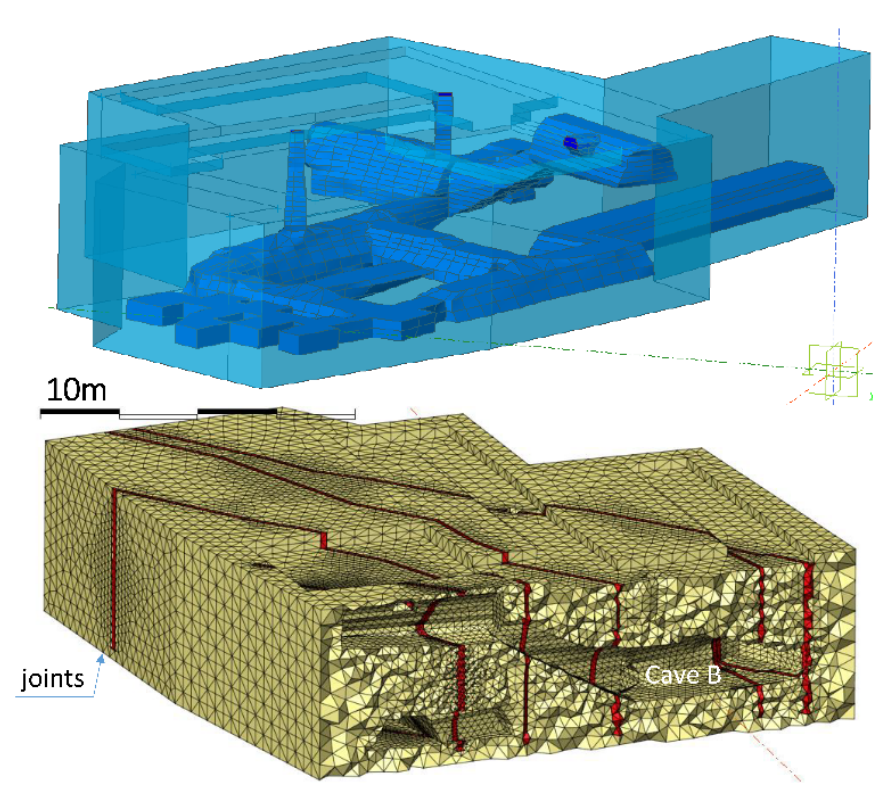

b)

Figure 11: Step \#5- Geometrical and numerical model : a) Cave A; b) Cave B with an hidden part of the mesh 
60

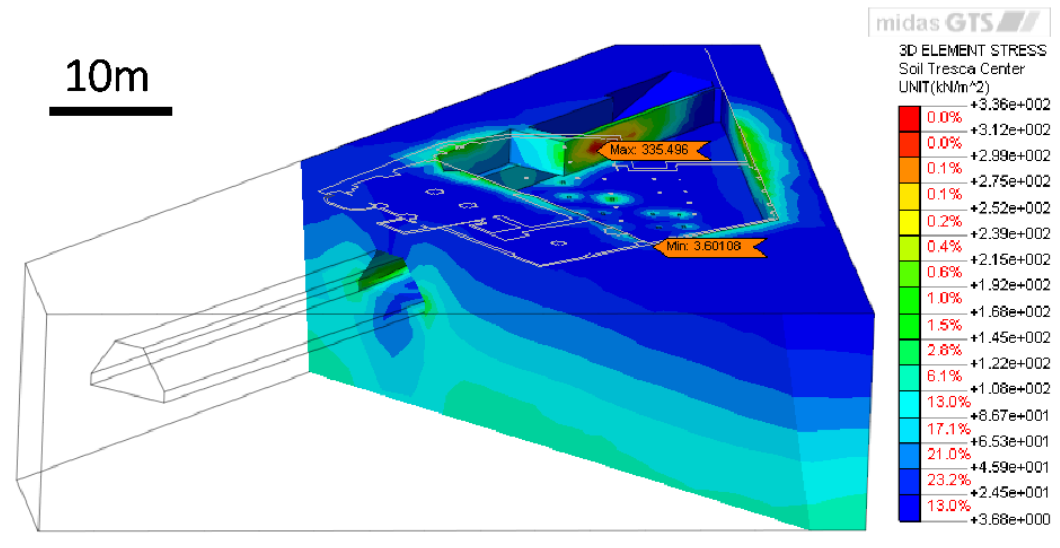

a)

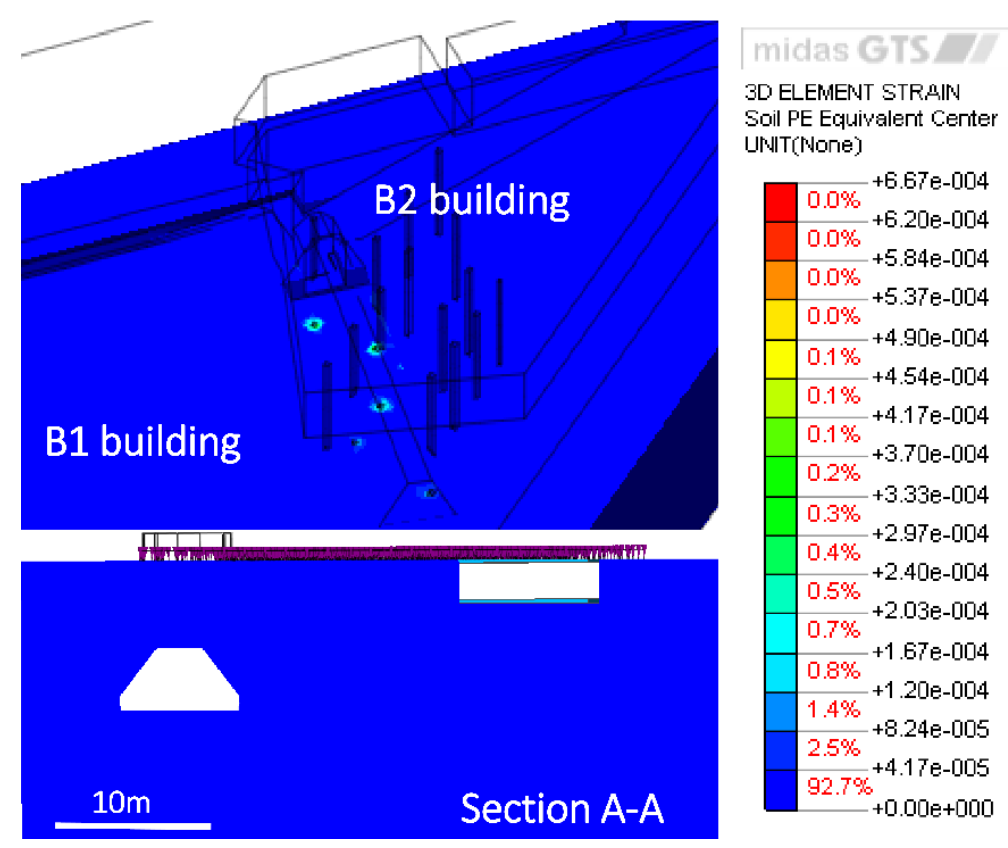

b)

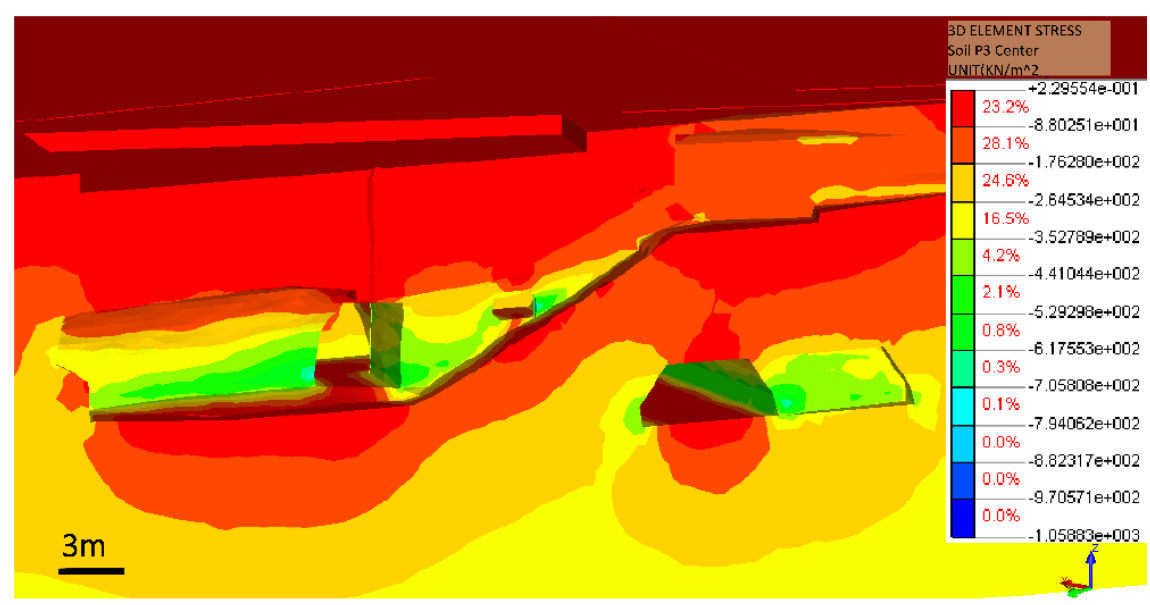

c) 


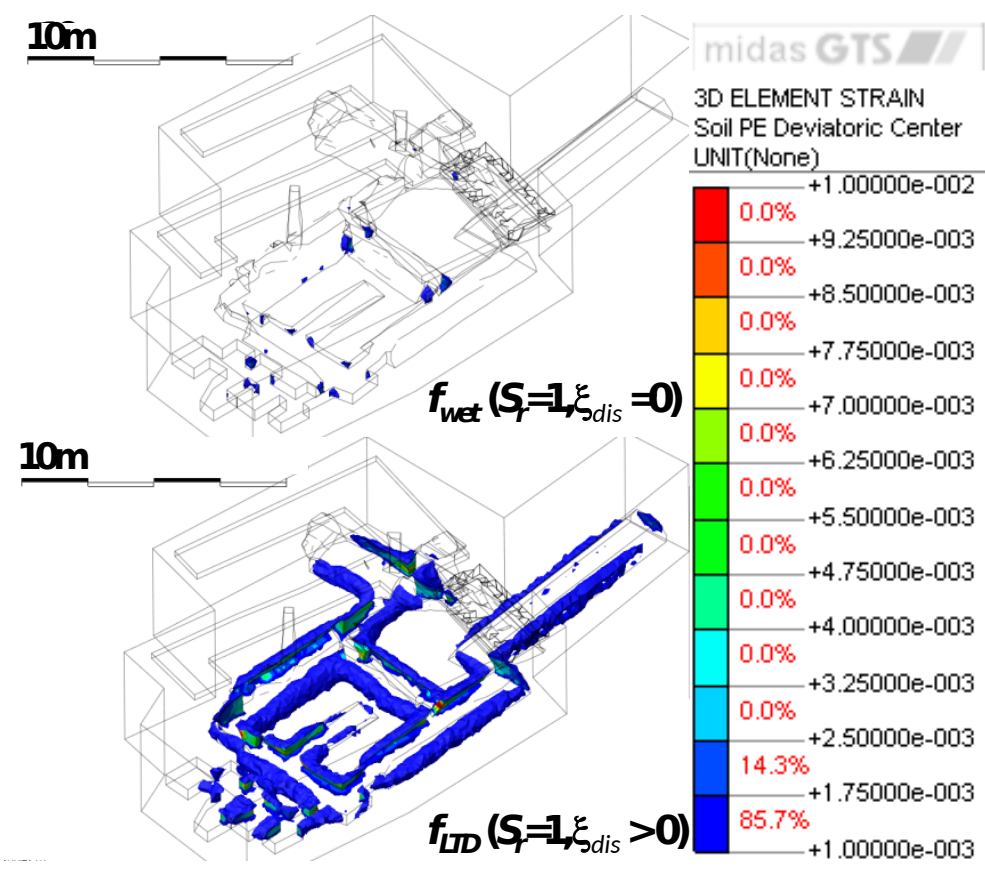

d)

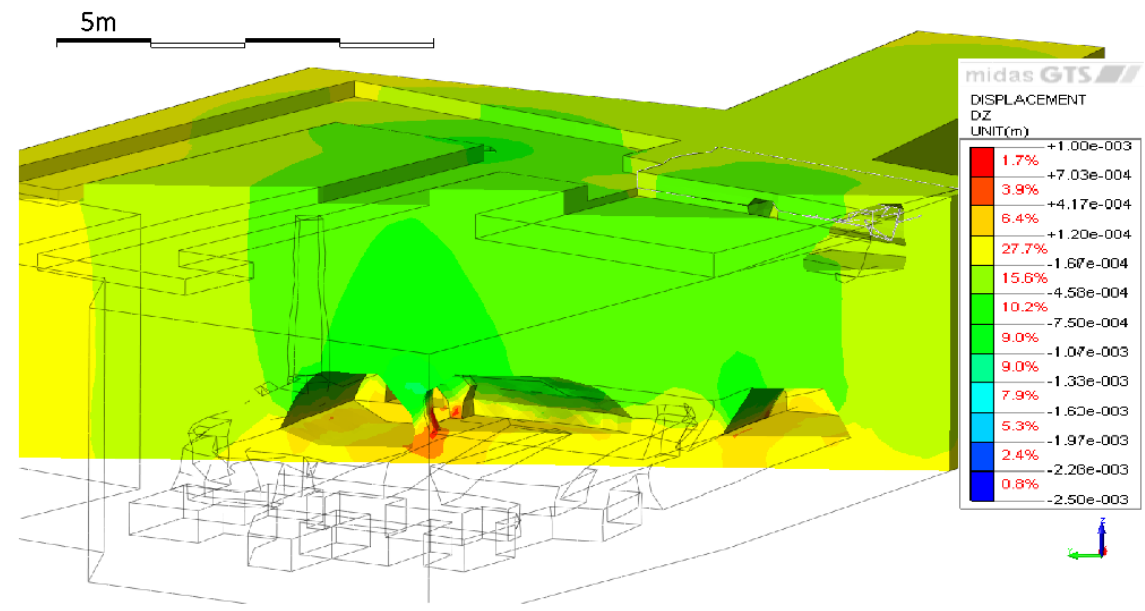

Figure 12: Step \#5-Numerical results (contours) - Cave A: (a) shear stresses; (b) plastic strains; Cave B: (c) maximum principal stresses (compression are negative) (d) plastic strains after a total saturation $\left(f_{\text {wet }}: S_{r}=1\right)$ and after a LTD process $\left(f_{L T D}\right)$ that correspond to a Strength Reduction Factor of 4,28; e) vertical displacement at $S_{r}=1$. 

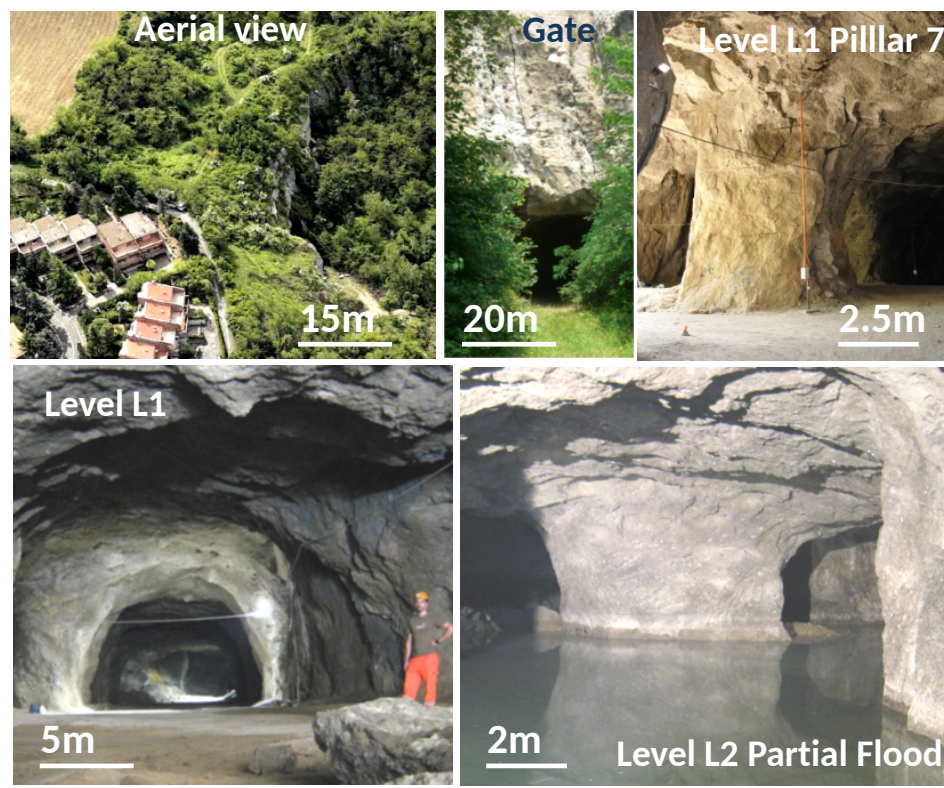

Figure 13: Step \#1- preliminary survey.

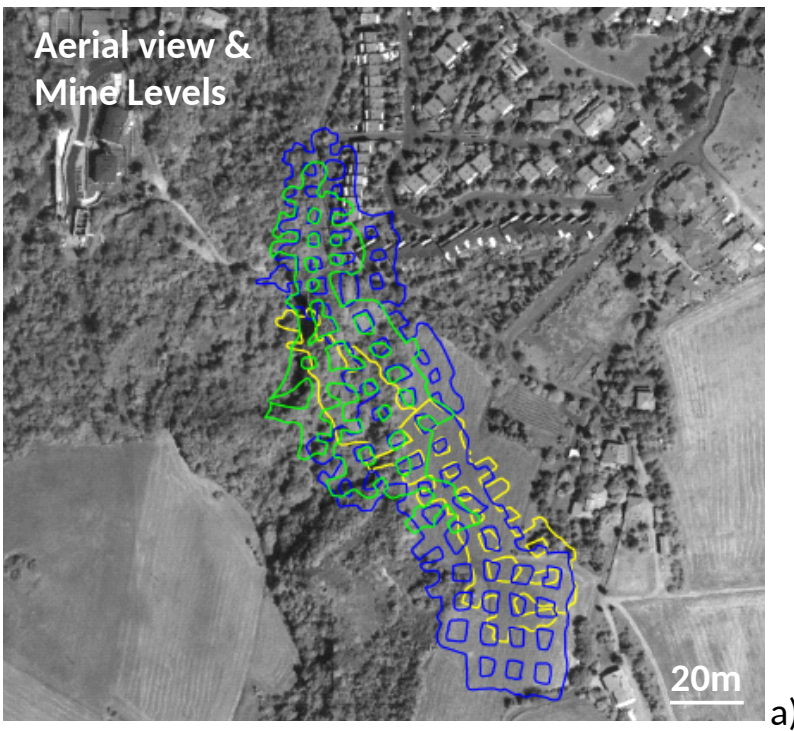

a)

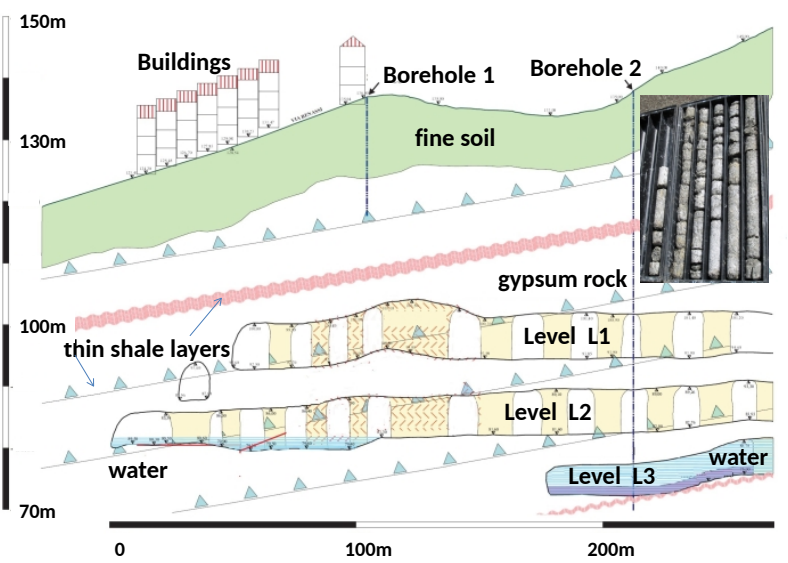

b)

Figure 14: Step \#1- Planar view (a) and section (b) of the abandoned mine system interacting with buildings. 

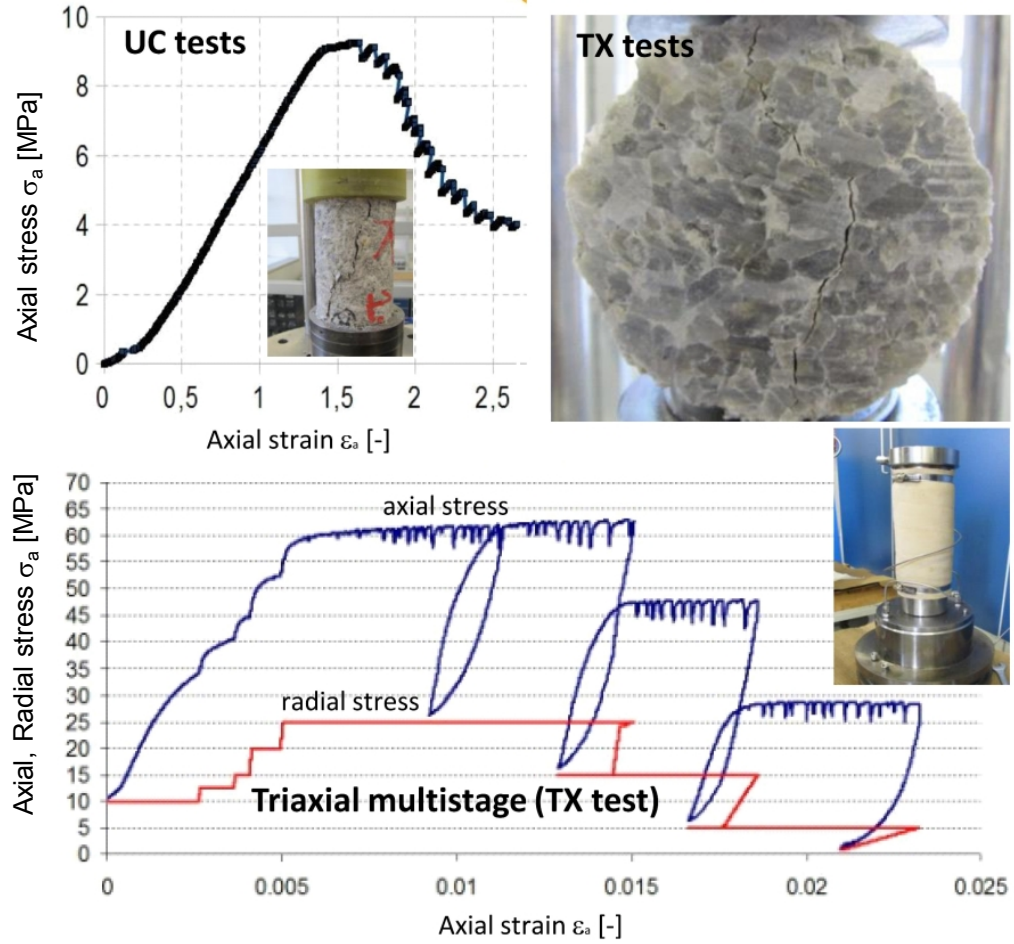

Figure 15: Step \#3- Experimental results for fresh gypsum (UR): UC (Uniaxial Compression), BT (Indirect Tensile Test) and TX test (multistage triaxial test).

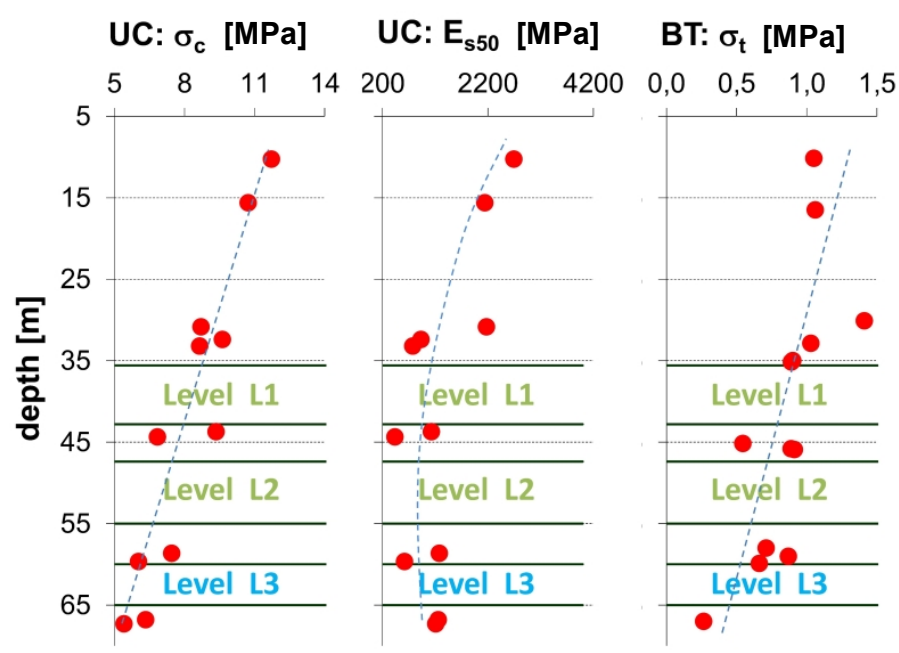

Figure 16: Step \#3- Experimental results: in situ existing weathering profile of compression strength, stiffness and tensile strength. 


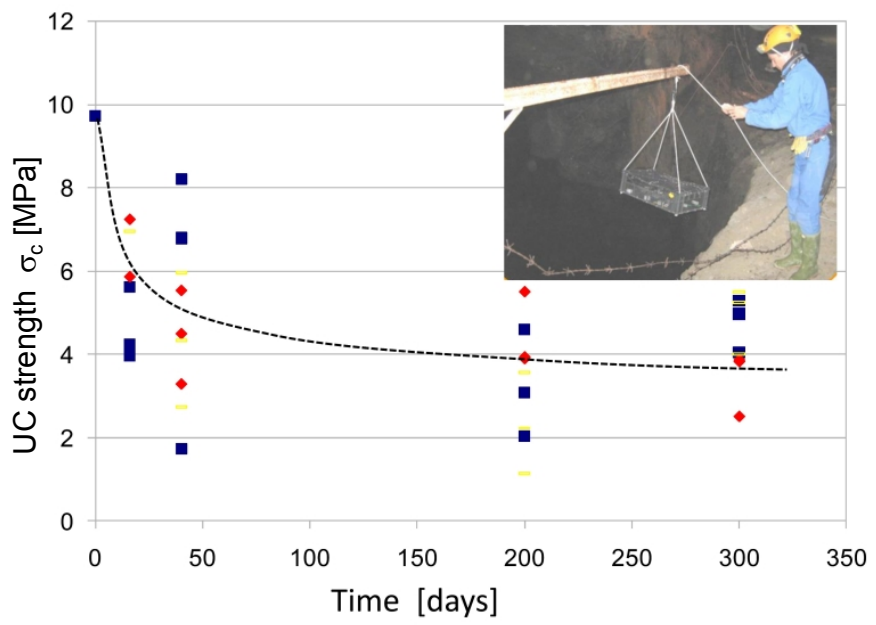

a)

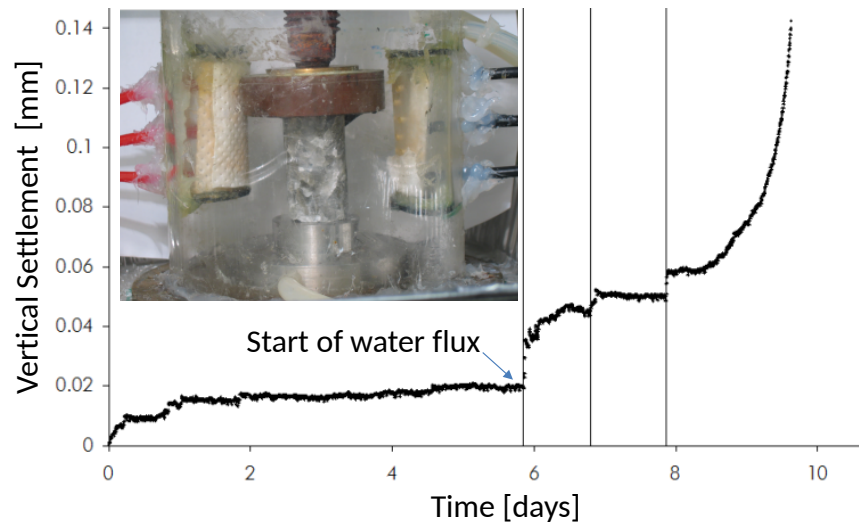

b)

Figure 17: Step \#3- Experimental results: (a) Decay resistance to uniaxial specimens immersed in situ (in the flooded quarry at Level L3); (b) Small-scale simulation of collapse of a pillar in a water flux.

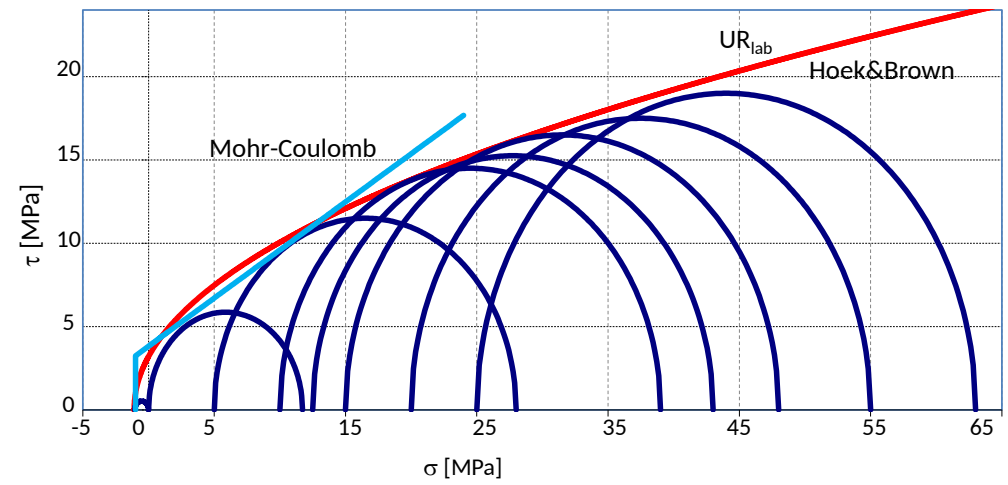




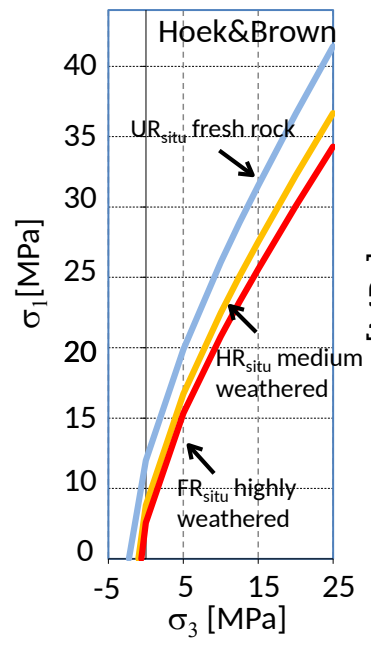

100

101

102

103

104

105

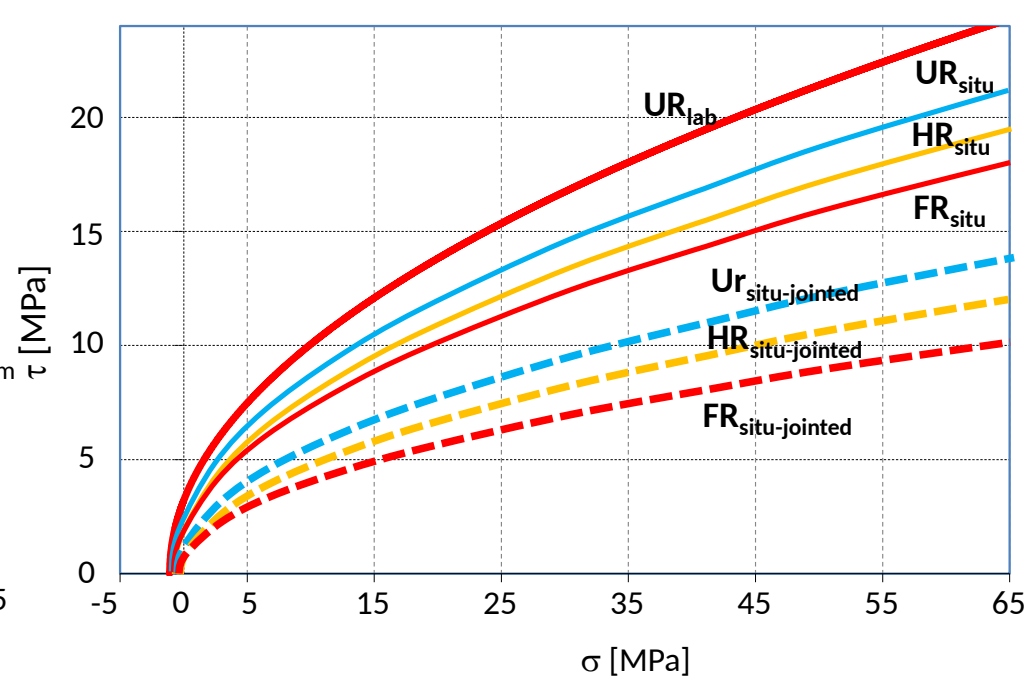

b)

Figure 18: Step \#4- Failure envelopes adopted for the gypsum: (a) fitting with HB and MC criterion; (b) Hoek and Brown failure loci for the in situ weathered gypsum;

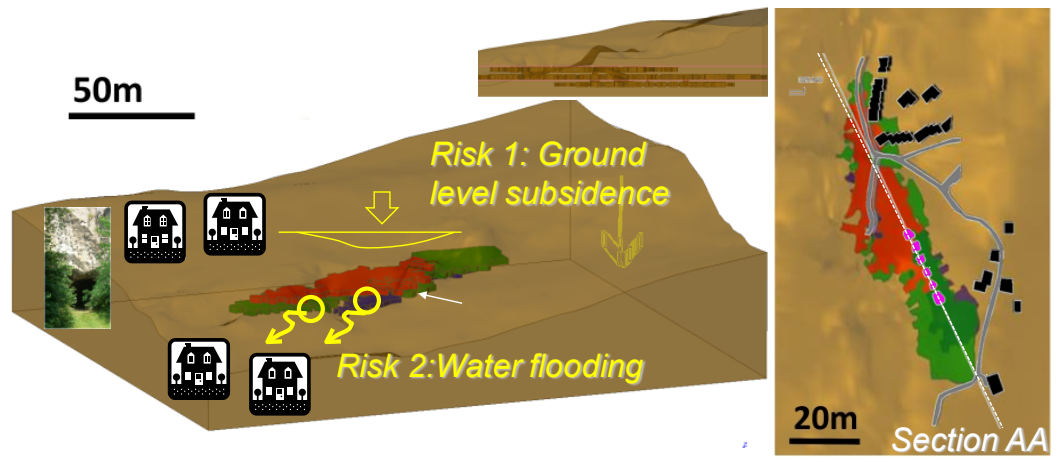

a)

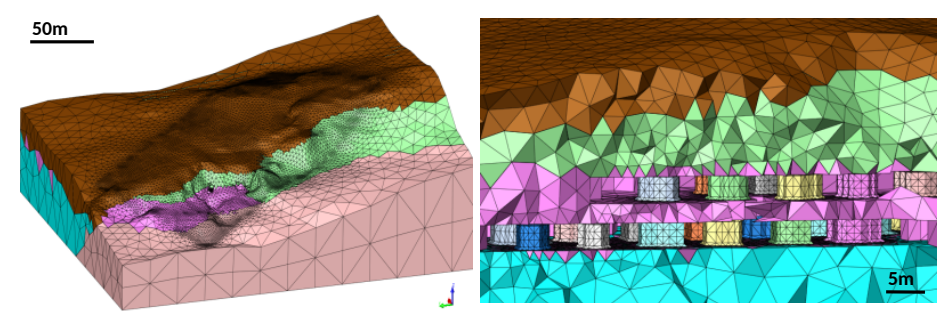

b)

Figure 19: Step \#5- Geometrical model and discretization mesh. a) Perspective view and top view of the solids; b) perspective view of the finite element mesh and detail of the mesh in the cave system. 


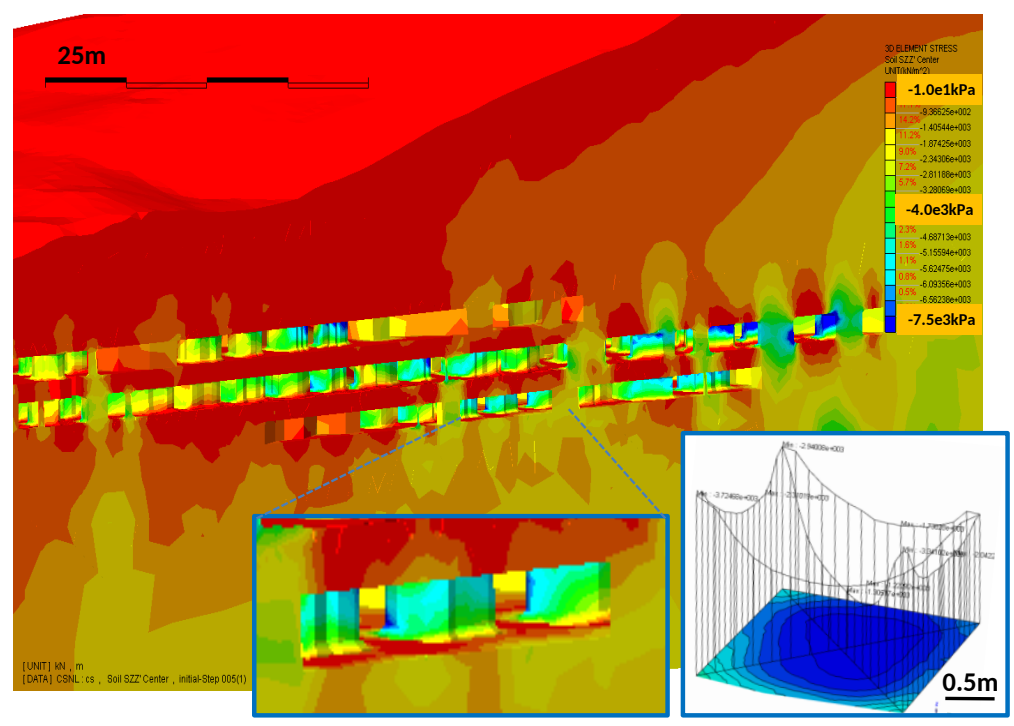

Figure 20: Step \#5 - Metodology 1 - Elastic analysis : Contour of the in situ vertical stress state of pillars evaluated by 3D FEM analyses; in the right bottom corner an example of the vertical stress diagram used to evaluate the average value of $\sigma_{\text {situ }}$ is shown.
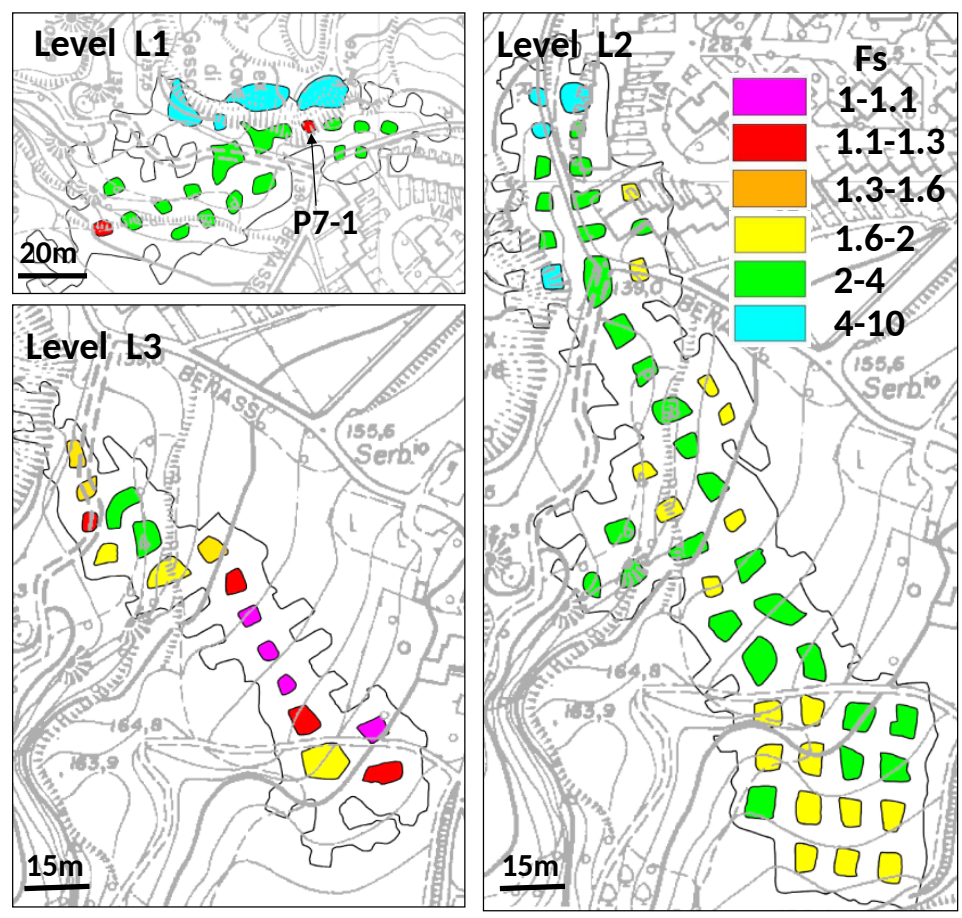

Figure 21: Step \#5 - Metodology 1 : Pillar safety factor evaluated by combining the in situ stress level and rock strength 


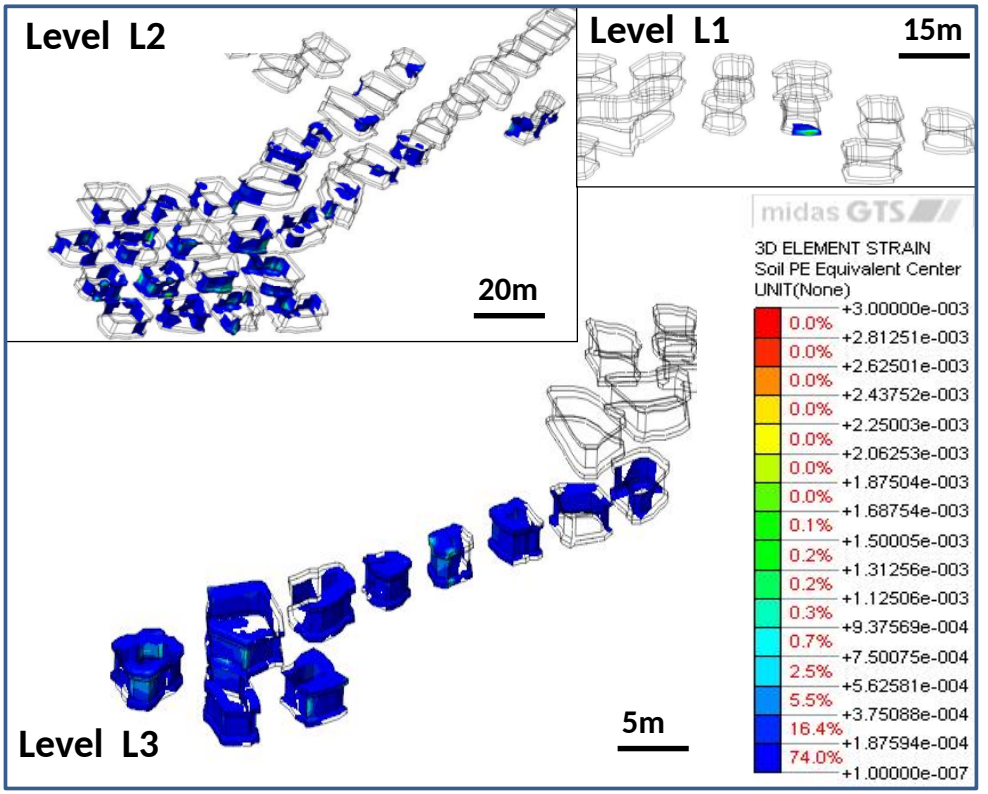

Figure 22: Step \#5 - methodology 2 -Numerical results: plastic strains at the present conditions

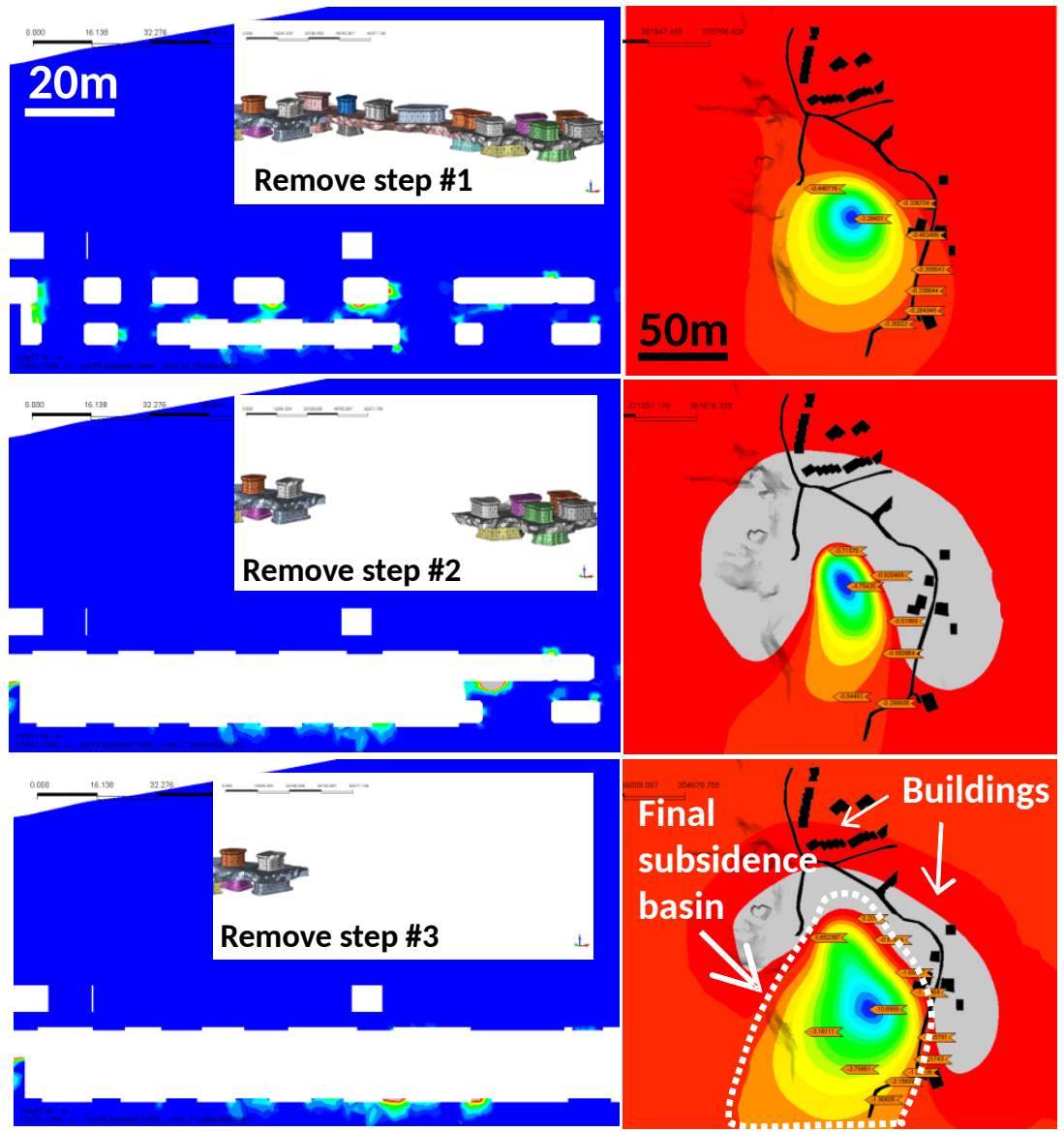

121 Figure 23: Step \#5: Evaluation of subsidence basin after removing the critical pillar and roof of level L3: Contour of plastic strain at section AA (left), contour of superficial subsidence (right) 


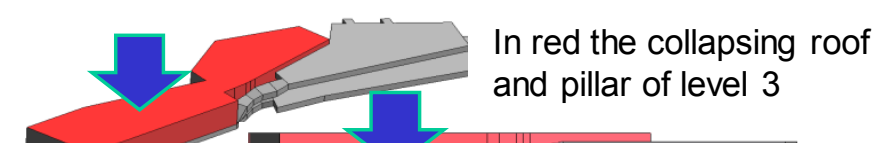

Figure 24: Step \#5 Forecast of the outgoing volume of water from level 1 in case of quick collapse of the entire roof of level L3

Table 1: Hoek and Brown (1997) failure criteria parameters for in situ condition without joints for the

\begin{tabular}{r|c|c|c|}
\hline Gypsum Rock & $\mathbf{U R}_{\text {situ }}$ & $\mathbf{H R}_{\text {situ }}$ & $\mathbf{F R}_{\text {situ }}$ \\
\hline$\sigma_{c i}[\mathrm{MPa}]$ & 11.72 & 8.39 & 6.36 \\
\hline$\sigma_{\mathrm{ti}}[\mathrm{MPa}]$ & -1.53 & -0.97 & -0.66 \\
\hline$m_{b}$ & 7.65 & 6.17 & 5.16 \\
\hline $\mathrm{s}$ & 1.00 & 0.51 & 0.29 \\
\hline$a$ & 0.50 & 0.50 & 0.50 \\
\hline$D($ Damage $)$ & 0.00 & 0.00 & 0.00 \\
\hline$E_{m}[\mathrm{GPa}]$ & 1.93 & 1.36 & 1.02 \\
\hline
\end{tabular}

Small water flooding from the mine system entrance $<2000 \mathrm{~m} 3$ 